\title{
Global-Scale Ionospheric Tomography During the 17 March 2015 Geomagnetic Storm
}

\author{
F. S. Prol ${ }^{1,2}$, T. Kodikara ${ }^{1}$, M. M. Hoque ${ }^{1}$, and C. Borries ${ }^{1}$ \\ ${ }^{1}$ Institute for Solar-Terrestrial Physics, German Aerospace Center (DLR), Kalkhorstweg 53, \\ 17235 Neustrelitz, Germany. \\ ${ }^{2}$ Department of Navigation and Positioning, Finnish Geospatial Research Institute (FGI), \\ National Land Survey of Finland (NLS), Geodeetinrinne 2, 02430 Kirkkonummi, Finland
}

Corresponding author: Fabricio Prol (fabricioprol@hotmail.com)

\section{Key Points:}

- Presents an advanced global-scale tomography of ionospheric electron density

- Demonstrates the capability of the tomography model to reproduce the system dynamics during a severe geomagnetic storm

- Validates the tomography results with multiple ground- and space-based data and compares with empirical and physical models

\begin{abstract}
The correct representation of global-scale electron density is crucial for monitoring and exploring the space weather. This study investigates whether the ground-based Global Navigation Satellite System (GNSS) tomography can be used to reflect the global spatial and temporal responses of the ionosphere under storm conditions. A global tomography of the ionosphere electron density is constructed based on data from over 2700 GNSS stations. In comparison to previous techniques, advances are made in spatial and temporal resolution, and in the assessment of results. To demonstrate the capabilities of the approach, the developed method is applied to the 17 March 2015 geomagnetic storm. The tomographic reconstructions show good agreement with electron density observations from worldwide ionosondes, Millstone Hill incoherent scatter radar and in-situ measurements from satellite missions. Also, the results show $\mathrm{tr}^{\text {th }}$ at the tomographic technique is capable of reproducing plasma variabilities during y:omagnetically disturbed periods including features such as equatorial ionization anomaly enhancements and depletion. Validation results of this brief study period show that the accuracy of our tomography is better than the Neustrelitz Electron Density Model, which is the model used as background, and physics-based thermosphere-ionosphere-electrodynamics general circulation model. The results show that our tomography approach allows us to specify the global electron density from ground to approximately $900 \mathrm{~km}$ accurately. Given the demonstrated quality, this global electron density reconstruction has potential for improving applications such as assessment of the effects of the electron density on radio signals, GNSS positioning, computation of ray tracing for radio-signal transmission, and space weather monitoring.
\end{abstract}

This article has been accepted for publication and undergone full peer review but has not been through the copyediting, typesetting, pagination and proofreading process, which may lead to differences between this version and the Version of Record. Please cite this article as doi: 10.1029/2021SW002889.

This article is protected by copyright. All rights reserved. 


\section{Plain Language Summary}

Computerized tomography allows the 3D imaging of several objects based on radio frequency signal measurements. Given the measurements and geometry of the current GPS (Global Positioning System) satellite constellation, there is an opportunity to apply tomography techniques and extract 3D snapshots of the Earth's atmosphere. This work presents an advanced global-scale tomography that can represent the electron density in the Earth's upper atmosphere in a relatively high spatial and temporal resolution in the region of approximately $100-1000 \mathrm{~km}$ above the Earth's surface; referred to as the ionosphere. The work also validates the tomography results with multiple ionospheric observations from satellites and ground-based radar instruments and compares with empirical and physical models. It is usually a challenge for models to reproduce the ionospheric system dynamics accurately during active space weather conditions, such as geomagnetic storms. This work, using the severe geomagnetic storm on 17 March 2015 as a case-study, shows that the tomography is well poised for this task. The developed method could be extended to benefit several applications, such as space weather monitoring, GPS positioning and navigation, as well as to improve our understanding of the morphology and dynamics of the ionosphere.

\section{Introduction}

Measuring the electron density in the ionosphere is an important step to improve our understanding of the solar-terrestrial environment impact on communication, surveillance, and navigation systems. Several methods can be applied to estimate the three-dimensional (3D) electron density in the ionosphere (Bust and Mitchell, 2008). In this context, the computerized ionospheric tomography (CIT) gained attention in the last three decades since it provides accurate observations of the ionospheric electron density over large areas (Austen et al. 1988, Norberg et al. 2018). The main products are 3D spatial fields of the electron density, which evolve with time in a series of snapshots. Over the last 20 years, several achievements have been obtained by CIT techniques. It has been demonstrated that these images can be used to describe the overall ionospheric plasma structure and its temporal evolution in the atmosphere. They have been successfully used to represent important ionospheric dynamics, such as travelling ionospheric disturbances (Chen et al. 2016, Bolmgren et al. 2020), geomagnetic storm signatures (Bust et al. 2007, Tang et al. 2015), polar tongues of ionization (Middleton et al. 2008, Pokhotelov et al. 2011) equatorial plasma bubbles (Comberiate et al. 2006, Prol et al. 2018a), and earthquake-induced disturbances (Hirooka et al. 2011, He and Heki, 2018). CIT is also shown to improve geodetic positioning techniques based on the Global Navigation Satellite System (GNSS) (Prol et al. 2019). So far, most CIT approaches have been applied regionally. However, there is a need to apply CIT techniques on a global scale since the correct representation of the electron density worldwide can provide a complete overview of the state of the electron density dynamics, which is crucial for monitoring and exploring the space weather.

Global-scale tomography for ionospheric electron density estimation has been introduced by Juan et al. (1997) and Hernández-Pajares et al. (1998). They have applied tomographic techniques based on carrier-phase measurements of the worldwide GNSS network operated by the International GNSS Service (IGS). The strategy adopted in both studies avoids aligning the phase-carrier with code measurements. They were later improved by spline and kriging interpolations with the Tomographic Ionosphere model (TOMION). The TOMION is the basis of the UPC (Universitat Politècnica de Catalunya) and UQRG (UPC Quasi-Rapid Global

This article is protected by copyright. All rights reserved. 
Ionospheric Map) products of IGS, which are nowadays presenting one of the most precise global ionospheric maps (Roma-Dollase et al. 2018). An important approximation required to solve the tomographic system in TOMION is the use of a few layers, such as two, three or four layers (Hernández-Pajares et al., 2020). The use of a few layers makes the tomography inversion system not dependent on any ionosphere background model; however, the global-scale CIT can further be improved by incorporating multiple layers of the ionosphere to accurately characterize the vertical distribution.

Besides tomography, data assimilation with numerical models can also be used to estimate the global electron density (e.g., Kodikara et al., 2021) but tomography is different from data assimilation techniques since tomography is not constrained by the internal physics of the model. Besides TOMION, She et al. (2017) developed a global tomography with a parameterized ionospheric electron density model based on eigenmode and least-square regression. This technique is often referred to as function-based tomography, where a set of spherical harmonic and empirical orthogonal functions (EOF) are used to capture the ionospheric features. Another recent approach was developed by Cheng et al. (2021) using a voxel-based technique, in which the fundamental difference is that voxel-based technique does not depend on polynomial coefficients (Yao et al. 2013). Using approximately 300 GNSS stations, Cheng et al. (2021) have reconstructed the global ionosphere with a resolution of $2.5^{\circ}, 5^{\circ}, 50 \mathrm{~km}$, and 1 hour in latitude, longitude, altitude, and time, respectively. This non-constrained reconstruction technique was applied with a parallel computing method in order to characterize the ionospheric anomalies of a storm event that occurred on September 7-8, 2017. As mentioned by the authors, the use of global data can pose problems to invert the 3D electron density in the ionosphere, requiring the development of new techniques that are capable of reproducing the ionosphere with higher temporal and spatial resolutions.

Built on previous work, it is reasonable to say that four of the main challenges to improve global scale tomography are related to the 1) enhancements of the spatial and temporal resolution of the 3D grid, 2) incorporation of TEC data with better global coverage, 3) development of realistic constraints, and 4) advances on the system geometry, i.e. incorporation of TEC measurements with distinct elevation angles. Based on such motivations, we have developed a technique which makes advances in the first three points. In this study, the objective is to provide advances on the development of a voxel-based CIT technique for mapping the global ionosphere accurately. In comparison to previous global-scale ionospheric tomography methods, we use a denser network of GNSS stations (approximately 2700), higher spatial and temporal resolution $\left(2^{\circ}, 2^{\circ}, 20 \mathrm{~km}\right.$, and 15 minutes in latitude, longitude, altitude, and time, respectively) and we incorporate optimized constraints to stratify the ionosphere in several layers. Additionally, the present tomography evaluation is considering a set of accurate in-situ electron density measurements in order to present a broader evaluation of the capabilities of the global-scale tomography for the digestion of the ionosphere under storm conditions. Despite the computational demands, we have incorporated constraints in the global tomography since it is an important step to stabilize the solution at locations with only a few GNSS measurements. The CIT technique is applied to the challenging case study of the geomagnetic storm on 17 March 2015, which is also known as the 2015 St. Patrick's Day storm. The evaluation of the reconstructed 3D electron density has been performed at distinct altitudes based on electron density measurements of ionosondes, incoherent scatter radars (ISRs), and in-situ measurements from the Defense Meteorological Satellite Program (DMSP), Gravity Recovery and Climate Experiment (GRACE), and Swarm missions. In addition to the model-data comparison, we

This article is protected by copyright. All rights reserved. 
highlight the capabilities of the CIT technique to represent ionosphere disturbances during the geomagnetic storm. The occurrence of strong enhancements and depletion of ionization with respect to quiet times (positive and negative ionosphere storms) has been described in many studies (e.g. Nava et al., 2016, Nayak et al., 2016, Borries et al., 2016, Zhang et al., 2017a). In our study, we pay special attention to the equatorial ionization anomaly (EIA) in order to understand whether the developed tomography can be used to reflect relevant spatial and temporal responses of the ionosphere during storm conditions.

\section{Tomography Formulation}

The basic quantity required to perform CIT is expressed by the integral of the electron density along radio frequency signal paths crossing the ionosphere. CIT is, therefore, mainly applied to solve an inverse problem using total electron content (TEC) measurements. A major source of TEC measurements nowadays is the growing number of ground-based GNSS receivers, which provide a substantially large spatial and temporal coverage of the ionosphere in comparison to several remote sensing instruments. The calibration of the STEC estimated in this work is based on the formulation provided by Prol et al. (2018b). As mentioned by Prol et al. (2018b), the STEC calibration is implemented in two steps. The first step estimates the Differential Code Bias (DCB) based on IGS Vertical TEC (VTEC) maps from the Center for Orbit Determination in Europe (CODE) solutions. The second step estimates ambiguities using the so-called phase leveling, where the ambiguity terms are determined by the mean difference of the phase and code measurements over one arc of data with no cycle slips. We have chosen this method since it has presented similar accuracy to ionosphere-free solutions when applied to GNSS precise point positioning.

In order to estimate a set of unknown electron density values based on the GNSS TEC measurements, the ionosphere is broken down into a grid of voxels with a specific spatial resolution and coverage. The equation to solve for the unknown electron density $x$ in each voxel is then given by Bust and Mitchell (2008) as:

$$
\mathbf{y}=\mathbf{A x}+\boldsymbol{\varepsilon}
$$

where $y$ is the vector of slant TEC (STEC) measurements, $A$ is composed by the path length of each GNSS signal inside the voxels, and $\varepsilon$ is the system and measurement noises.

The ground-based GNSS measurements only provide a limited number of viewing angles of the ray path. Due to the almost vertical GNSS geometry of the ground-based observations, the direct solution of Equation (1) is ill-conditioned to describe the ionosphere using several layers. Ionospheric imaging by CIT is therefore a challenge due to this incomplete geometrical coverage that renders an ill-posed system (e.g., Pryse et al. 1998, Mitchell and Spencer 2003, Wen et al. 2008, Yao et al. 2014, Zheng et al. 2018, Ssessanga et al. 2021). Hernández-Pajares et al. (1999), for instance, use Equation (1) with only two layers in order to solve the ill-conditioned problem. The incorporation of radio-occultation measurements is a viable option to improve the GNSS geometry (Yin and Mitchell 2005) and thus the number of layers. The number of low Earth orbit (LEO) satellites is still sparse for high vertical and temporal resolutions. Additionally, the length of the unknown vector $x$ in Equation (1) is directly proportional to the number of voxels.

Considering the ionospheric dimensions, a high-resolution 3D grid estimation can, therefore, cost an intense computational effort, especially on a global scale. In this regard, approximations and constraints on Equation (1) are required to gain computational efficiency and solve the illconditioned system with high vertical resolutions.

This article is protected by copyright. All rights reserved. 
First CIT applications to represent multiple layers of the ionosphere were based on 2D regional geometries using iterative algorithms, such as the Algebraic Reconstruction Technique (ART) (Austen et al. 1988) and the Multiplicative ART (MART) (Raymund et al. 1990). In principle, ART and MART provide fast updates of the ionosphere without applying constraints on the estimation, which poses a problem since 3D iterative tomographic algorithms are affected by the almost vertical geometry provided by the GNSS measurements. Some studies have shown that constrained techniques can avoid this problem and improve the overall specification of electron density (e.g., Wen et al. 2010, Liu et al. 2010, Debao et al. 2015, Yao et al. 2020). The constraint dependence can add to the computational burden due to the additional matrix multiplications. In addition to the matrix multiplications, some constrained techniques require a large dataset with many intersections of the GNSS signals. Therefore, on a global scale, the large number of unknowns $x$ together with several data gaps precludes the possibility of using the most sophisticated constrained techniques, such as the proposed by Seemala et al. (2014). In order to gain both computational efficiency and accurate specification of electron density, the CIT technique in this study combines the fast updates provided by ART with the optimized constrained technique introduced by Prol et al. (2021).

ART solves the least square problem based on an iterative algorithm. The initial value at iteration $k=1$ for $x_{j}^{k}$ is given by the electron density from the background model. The electron density in each voxel of the background model is then updated based on the difference between the TEC observations $(y)$ and background model TEC $\left(\sum_{j}^{N} A_{i j} x_{j}^{k}\right)$ iteratively for each subsequent $k$. For a given voxel $j$ and signal $i$, ART can be formulated as (Wen et al. 2010),

$$
x_{j}^{k+1}=x_{j}^{k}+\gamma_{i j} \frac{\left(y_{i}-\sum_{j=1}^{N} A_{i j} x_{j}^{k}\right)}{\sum_{j=1}^{N} A_{i j}^{2}} A_{i j}
$$

where $\gamma$ is the relaxing parameter, $y_{i}$ is the ith TEC observation, $A_{i j}$ is the path length inside the voxel $j$ for signal $i$, and $\mathrm{N}$ is the total number of voxels. The relaxing parameter usually varies from $0<\gamma<1$ in order to guarantee the convergence of the estimation.

In this study, we use the relaxing parameter from Prol et al. (2021), which helps to stabilize the ill-conditioned solution with no relevant additional computational efforts, since it does not incorporate a set of new matrix multiplications. This relaxing parameter is reproduced here as follows:

$$
\gamma_{i j}=0.2 * x_{j}^{0} / x_{\max }^{0}
$$

where $x_{j}^{0}$ is the electron density given by the background model and $x_{\text {max }}^{0}$ is the maximum electron density along the GNSS signal. The constant 0.2 controls the iteration convergence.

Equations (2) and (3) can be solely used to provide good specifications of the electron density ionosphere at regions with a dense GNSS network. However, a major issue on the global tomography relates to the sparse GNSS receiver locations, leading to several data gaps. In this study, similar to Prol et al. (2019) and further validated by Zheng et al. (2020), we use VTEC data together with STEC to increase the spatial coverage of data. To improve the solution over the oceans, we have incorporated VTEC observations obtained by the Global Ionospheric Maps (GIMs) from CODE, which provides a smooth interpolation of the data gaps. The VTEC values obtained from GIMs are first applied to Equations (2) and (3) in order to provide an initial correction on the background. Then, both equations are used again to update the 3D grid using

This article is protected by copyright. All rights reserved. 
the STEC observations of each local GNSS station. Afterwards, the regularization process of Heise et al. (2002) is used to calculate the electron density in the remaining empty voxels.

The background 3D electron density is specified by the Neustrelitz Electron Density Model (NEDM), which well describes climatological patterns of the ionosphere and plasmasphere (Jakowski and Hoque, 2019). The spatial distribution is defined with a $2^{\circ} \times 2^{\circ} \times 20$ $\mathrm{km}$ resolution for latitude, longitude, and altitude, respectively, for both the background and tomography. The vertical distribution ranges from 50 to $20.000 \mathrm{~km}$, covering from the bottomside ionosphere until the GNSS orbit height in the plasmasphere. The time resolution is 15 minutes, i.e., the electron density in each grid cell is defined to remain constant over a time period of 15 minutes. In this regard, the selected spatial and temporal resolution can be considered high for global scale tomography since there is a great challenge on the usage of higher resolutions due to the number of unknowns in the imaging system. Although this resolution may not be enough to capture very fine regional structures of the ionosphere, such as plasma bubbles, the defined resolution is sufficient to capture quite a few signatures and disturbances of the analyzed geomagnetic storm.

\section{Data and Case Study}

In each reconstruction step, the input STEC data for the tomography scheme are obtained from eight GNSS networks with a total of approximately 2700 GNSS stations. Figure 1 shows a map of these GNSS stations. We used data from the Global Positioning System (GPS) collected by the continuously operating GNSS networks of Africa (AFREF - African Geodetic Reference Frame), South Africa (TrigNet), Argentina (RAMSAC - Red Argentina de Monitoreo Satelital Continuo), Australia (ARGN - Australian Regional GNSS Network), Brazil (RBMC - Rede Brasileira de Monitoramento Contínuo), Europe (EUREF - European Reference Frame), United States of America (NOAA - National Oceanic and Atmospheric Administration's) and IGS.

Our method is validated using ionosonde measurements from the Global Ionosphere Radio Observatory (GIRO) network (Reinisch and Galkin, 2011) and reference electron density of ISR observations at Millstone Hill. To ensure a sufficient quality of the ionosonde measurements, we adopt the automatically scaled data from the GIRO network, ignoring values with a Confidence Score (C-Score) equal to zero or unknown precision. In addition, we remove all data from the ISR measurements with the standard deviation of the electron temperature larger than $500 \mathrm{~K}$ and only profiles at altitudes lower than $600 \mathrm{~km}$ (empirically observed cut off for outliers) are kept. For the topside ionosphere, we compare results with in-situ electron density measurements of DMSP, GRACE and Swarm missions. The DMSP satellite orbit is materialized at an altitude of approximately $830 \mathrm{~km}$ above the Earth, GRACE is flying at an approximate altitude of $500 \mathrm{~km}$ and Swarm-A orbit altitude is around $462 \mathrm{~km}$. As reference for the DMSP data, we are relying on the scintillation meter (SM) of the satellite number F15, which provides plasma density by a simple faraday cup (Hairston, 2018). We have manually checked the occasional SM glitches and removed them when necessary. GRACE instruments are equipped with the K-band ranging (KBR) system, which allows the derivation of high-precision electron density measurements (Xiong et al. 2015, Xiong et al. 2021). In other words, no preprocessing has been performed. For the Swarm mission, data from the Langmuir probes of satellite A is used to measure the electron densities (Knudsen et al., 2017).

This article is protected by copyright. All rights reserved. 


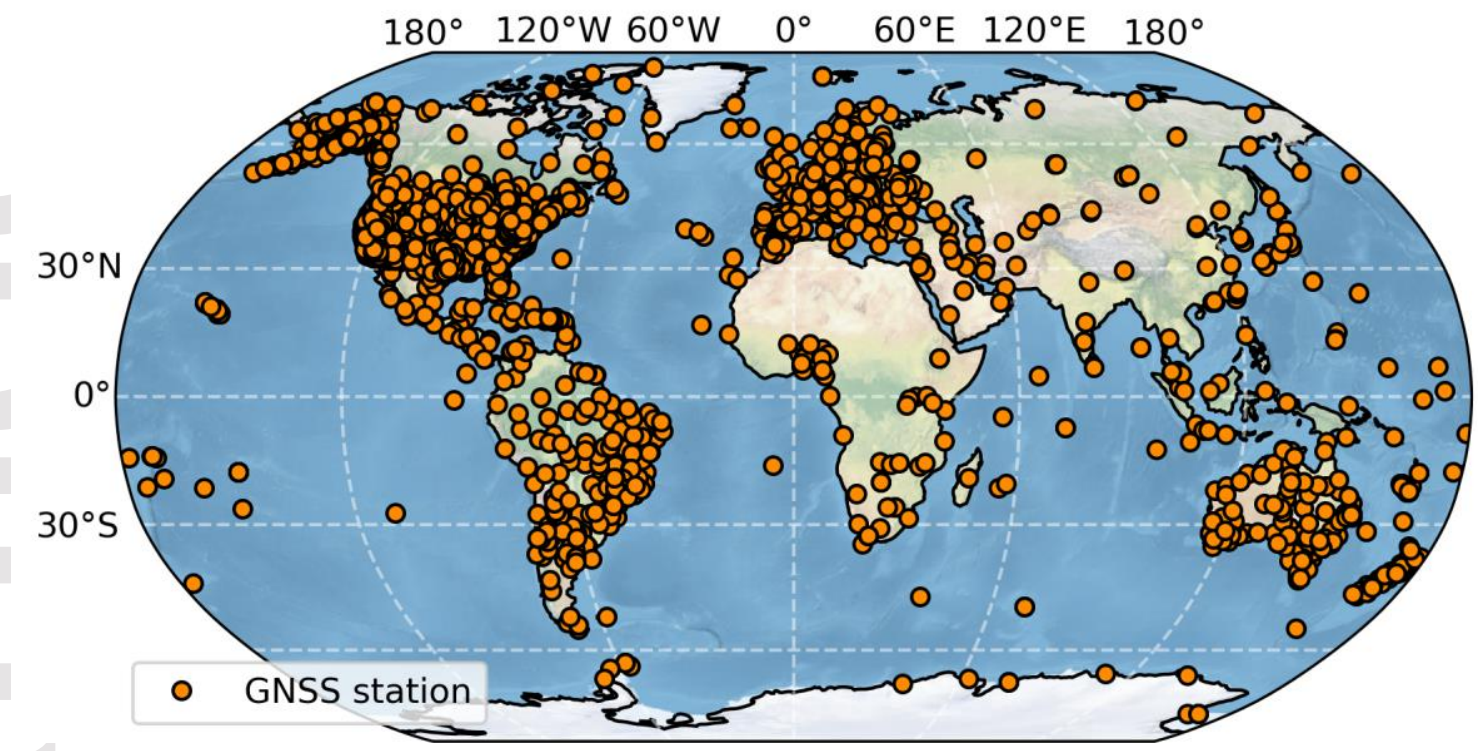

Figure 1. GNSS receiver locations used in the tomographic reconstruction.

The analyzed disturbed period relates to the St. Patrick's Day geomagnetic storm, 17 March 2015, which occurred after a coronal mass ejection of the Sun arrived at Earth at 04:45 UT. The interplanetary magnetic field component turned southward around 07:30 UT on 17 March and the symmetric ring current (SYM-H) index started to gradually decrease, marking the main phase of the storm (Astafyeva et al., 2015). The main phase lasted until a minimum SYM$\mathrm{H}$ value of $-233 \mathrm{nT}$ was reached at 22:45 UT. Then a slow recovery phase started. Given the strength of this storm, it can be considered a challenging scenario for CIT. For the analysis of the CIT quality, a total of seven days has been selected, referring to the days of the year (DOYs) 73 to 79 (14-20 March 2015). DOYs 73 to 75 can be considered as quiet times, while DOY 76 presents the storm main phase period of March 17. The remaining DOYs relate to the recovery phase.

Many of the ionosphere perturbations during the St. Patrick's Day storm 2015 have been analysed and published already. Next to the occurrence of strong positive and negative ionosphere storms (e.g. Nava et al., 2016, Nayak et al., 2016, Borries et al., 2016, Zhang et al., 2017a), also other typical ionosphere storm perturbations have been observed during St. Patrick's Day 2015. For instance, the equatorward shift of the main ionosphere trough in the high-latitudes has been described by e.g. Polekh et al. (2017). The formation of a tongue of ionization (TOI) in the polar cap region has been observed and modelled by Liu et al. (2016) and Huba et al. (2017). Also, strong scintillations have been described in both polar regions in D'Angelo et al. (2018). Broad Plasma Depletions (BPDs), which represent plasma depletions whose longitudinal and latitudinal scales are much greater than those of normal plasma bubbles, have also been reported for the St. Patrick's Day storm by Kil et al. (2016). Travelling Ionospheric Disturbances (TIDs,) have been analyzed by Borries et al. (2016) and Zakharenkova et al. (2016) for this event and Lu et al. (2020) added modelling results to these TID studies. Astafyeva et al. (2015) and other publications reported hemispheric asymmetries in the storm evolution. Also, a superfountain effect has been observed for the St. Patrick's Day storm 2015 e.g. by Nayak et al. (2016) and Fagundes et al. (2016). This means that the two crests of the EIA, which are usually at about $15^{\circ}$ to the North and South of the equator at quiet times, increase in electron density and shift in the direction towards mid-latitudes. This effect results from the magnetosphere driven penetration

This article is protected by copyright. All rights reserved. 
electric fields imposing on the normal background zonal electric fields (e.g. Kelley, 1989). The following results will mainly focus on the description of changes in the EIA and fountain effect.

\section{Results}

\subsection{Overview of the main storm features observed by tomography}

Figure 2 shows the VTEC maps from tomography from 16 to 18 March 2015 (DOY 7577) as well as the VTEC by NEDM during DOY 75. The main phase of the storm occurred on DOY 76, and DOY 77 was part of the recovery phase. DOY 75 is the quiet pre-storm day. The $\mathrm{x}-$ axis is the geographical latitude, the right $y$-axis gives the longitude, and the left $y$-axis gives the universal time. Figure 2 shows these VTEC maps from 0 to 22 UT for every 2 hours during each day. The VTEC maps by NEDM are similar on all three days (only DOY 75 is shown). In comparison to the background model NEDM, it is clear that significant updates were performed by tomography, such as a more evident EIA representation, as well as higher VTEC values in the low-latitudes and lower VTEC values during the nighttime and at the high-latitudes. During 0 to 14 UT, we can see very similar aspects between DOY 76 in comparison to DOY 75, which can be considered as a quiet day. Therefore, no disturbances were observed in this time interval. On the other hand, storm signatures are quite evident in the tomographic VTEC maps after 16 hours UT on DOY 76, where we can find a significant VTEC enhancement. Maximum VTEC values during the quiet period are observed around 70 TECU (TEC Units), being 1 TECU = $10^{16} \mathrm{el} / \mathrm{m}^{2}$, and maximum VTEC values during the disturbed period are observed around 90100 TECU at 18 UT. The enhanced VTEC condition lasts until the beginning of DOY 77, when an electron density depletion is observed. After 4 hours UT, smaller VTEC values are obtained and the overall VTEC structure is more confined at the equatorial region in comparison to DOY 75. This indicates an EIA inhibition, which lasts until 20 UT of DOY 77.

This article is protected by copyright. All rights reserved. 


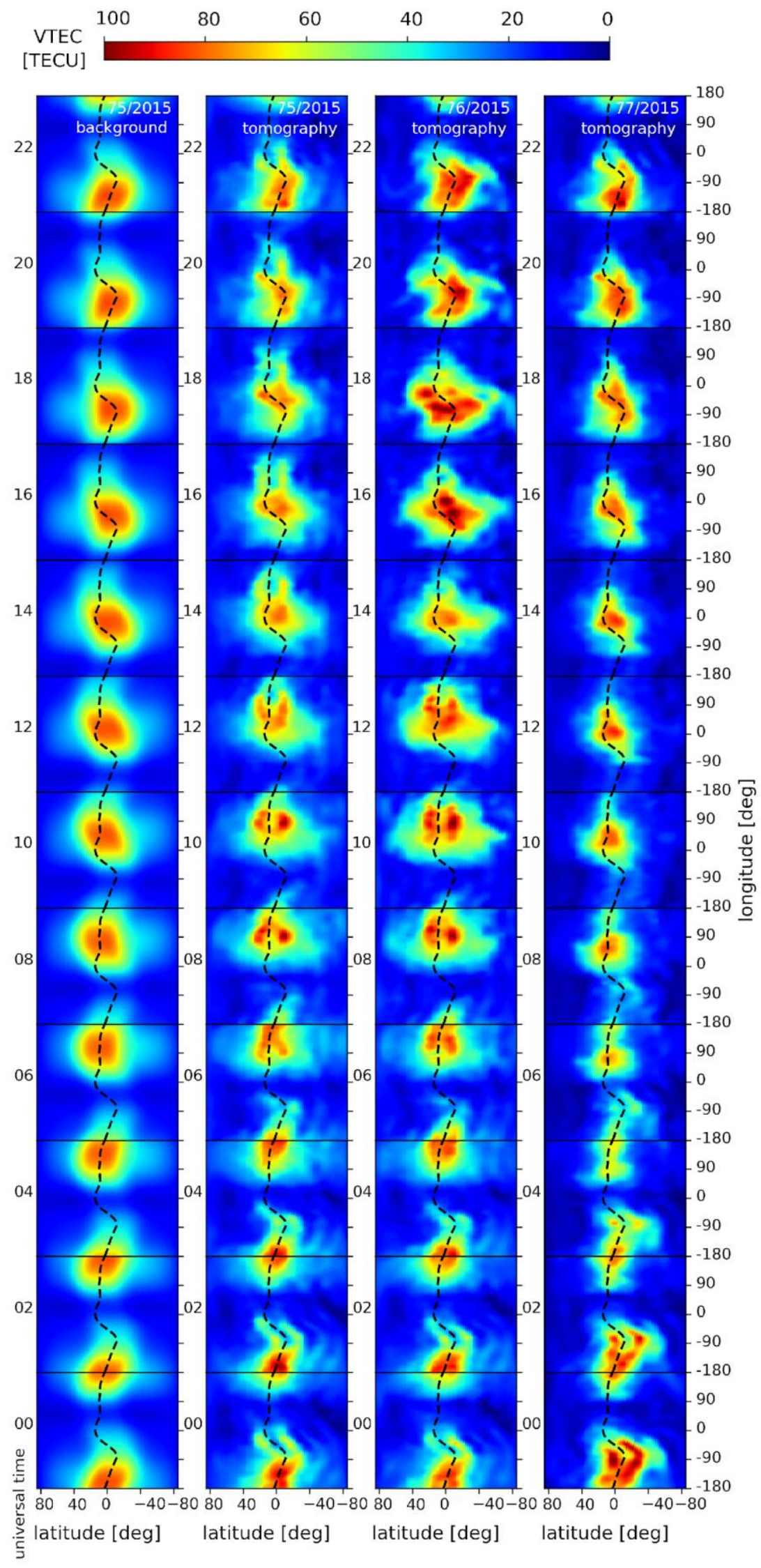

This article is protected by copyright. All rights reserved. 
Figure 2. VTEC maps in TECU obtained from the background and tomography during DOYs 75,76 and 77 of 2015. The $x$-axis represents the geographical latitude. The right $y$-axis shows the longitude and the left y-axis shows the universal time. Results are presented in two-hour increments from 0 to 22 UT with each VTEC map separated by a solid black line. The dashed black lines represent the geomagnetic equator.

A more detailed view of the electron density profiles obtained by tomography are shown in Figure 3. The slices in terms of altitude and geographic latitude refer to the longitude section $60^{\circ} \mathrm{W}$. Figure 3 demonstrates the capability of the global tomography to represent vertical structures of the ionosphere. The tomography electron density profiles are shown in the top three panels at DOYs 75, 76, and 77. The bottom two panels show DOY 75 subtracted from DOYs 76 and 77. Each column from left to right shows the variation from 17 to 18.75 hours UT, which reflect the period of the instances of the highest variabilities in the VTEC maps. The variability in electron density on DOYs 75 and 77 is relatively low compared to DOY 76. At 17 UT on DOY 76, an enhancement in electron density in the equatorial region is visible. And then the enhancement intensifies on either side of the equator until 18 UT. It is apparent that the electron density in the Southern hemisphere enhances more than the Northern hemisphere after 18 UT on DOY 76. The level of enhancement in DOY 76 is around $9 \times 10^{11} \mathrm{el} / \mathrm{m}^{3}$, as shown in the fourth panel, which is more pronounced in the Southern hemisphere. An electron density decrease is then observed in the mid-latitudes of the Northern hemisphere around $3 \times 10^{11} \mathrm{el} / \mathrm{m}^{3}$. In the recovery phase of the storm, a decrease in electron density is observed in the Southern hemisphere, reaching a minimum decrease of $10^{12} \mathrm{el} / \mathrm{m}^{3}$, as shown in the last panel. Therefore, the results show that electron density can vary significantly within a few hours during disturbed conditions and remain relatively steady under quiet or recovery conditions; however, the magnitude of the electron density decrease can be more intense in the recovery phase than the increase in the main phase.

This article is protected by copyright. All rights reserved. 


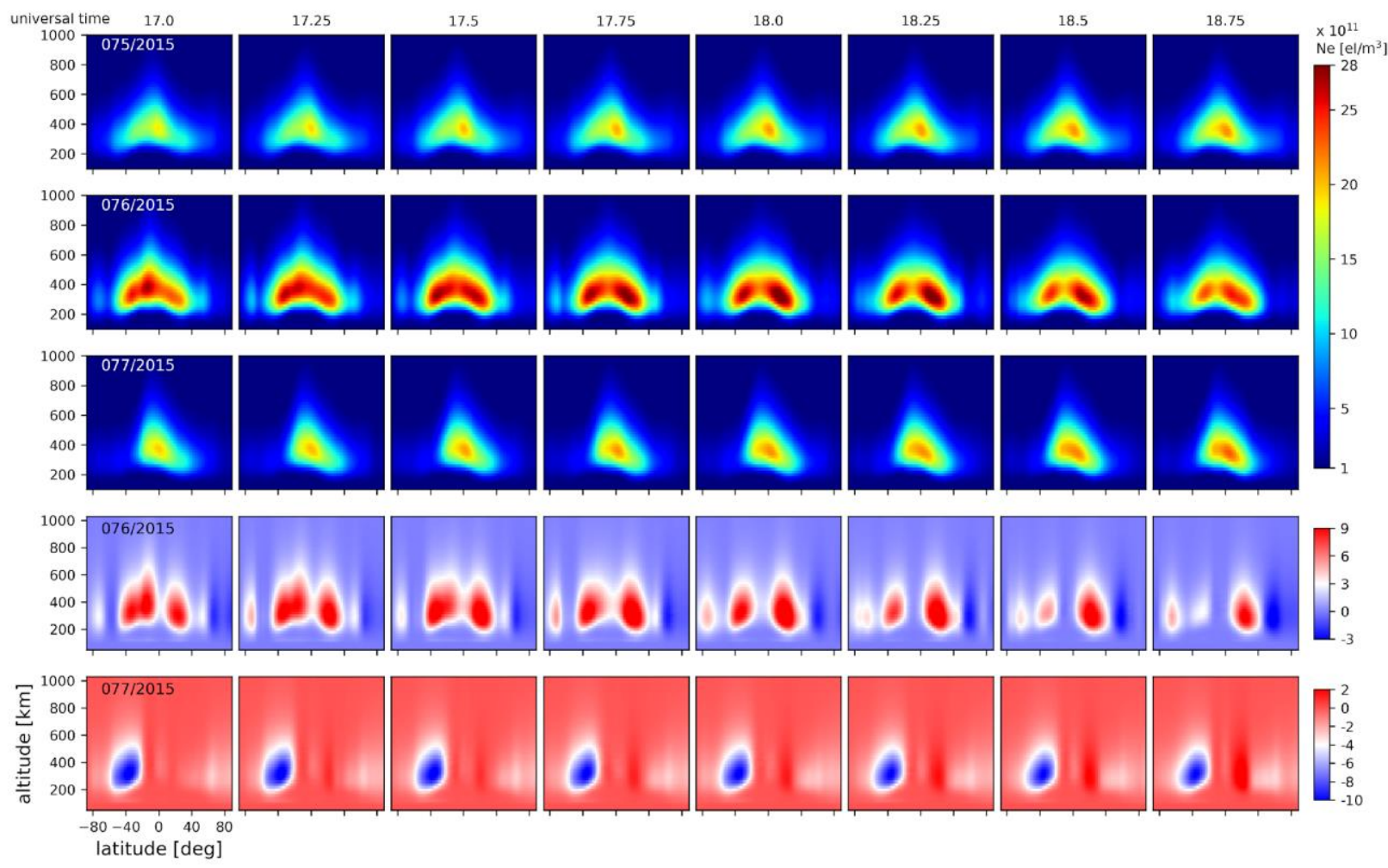

Figure 3. The first three rows of panels show electron density profiles obtained by tomography at DOYs 75,76 and 77 for the longitudinal sector $60^{\circ} \mathrm{W}$. The bottom two rows show the difference of the electron density profiles during DOYs 76 and 77 compared to DOY 75, indicating enhancements and depletions.

To explore the reconstructed EIA distributions in more detail, Figure 4 shows the electron density distribution over distinct altitudes at 18 UT. As it can be seen, the EIA crests are strongest and clearly distinguishable in the altitude range 290 to $300 \mathrm{~km}$. With increasing altitude, the maximum electron density gets closer to the geomagnetic equator. While the differences between the electron density distributions of DOYs 75, 76 and 77 are significant in the altitude range 290 to $300 \mathrm{~km}$, it is not so evident at $450 \mathrm{~km}$. During DOY 76, the EIA crests have larger distance from the geomagnetic equator than during DOY 75 and 77 . We can observe asymmetries between the Southern and Northern crests, presenting a higher level of the plasma density in the Northern hemisphere. During the recovery phase in DOY 77, the EIA crests are suppressed at all altitudes.

This article is protected by copyright. All rights reserved. 

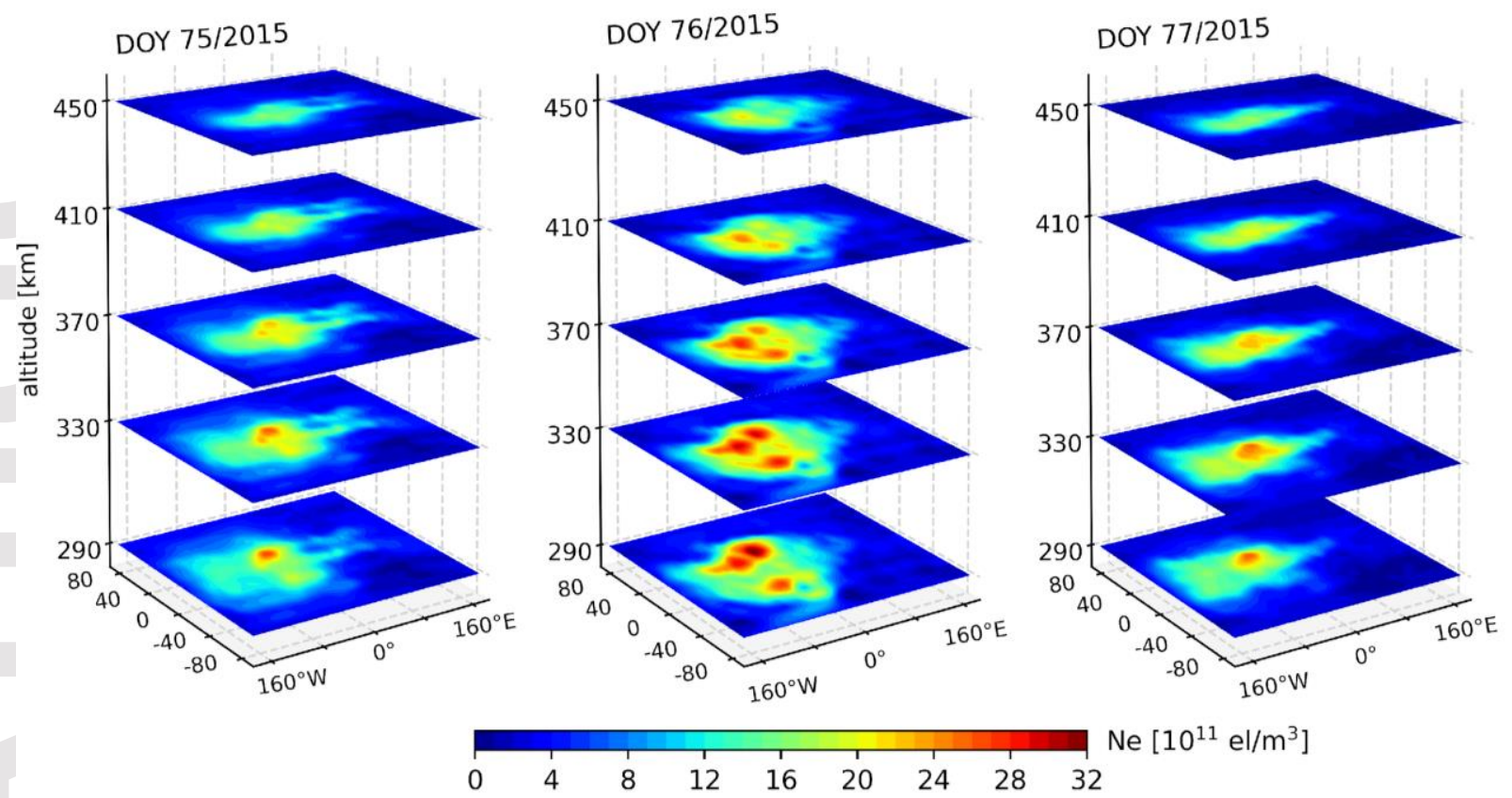

Figure 4. Electron density maps obtained by tomography at 18 UT on DOYs 75, 76 and 77 of 2015. Each row shows the latitude-longitude distribution of electron density at different altitude levels.

To illustrate a specific analysis on the EIA crests, Figure 5 shows the EIA development over time together with the SYM/H index. The top panel shows the electron density at the peak height $(\mathrm{NmF} 2)$ in terms of latitude by universal time. We fixed the local time at 15 hours to represent the EIA dynamics close to the highest ionization locations. Our investigation also presents a segmentation of the Southern (blue line) and Northern (red line) EIA crests. The segmentation was conducted by computing the latitudinal location of the maximum NmF2 values for the South and North directions. The middle panel gives a closer look of the maximum NmF2 latitudes by the solid lines. The dashed line stands for the differences between DOY 76 and 75 , as well as between DOY 77 and 75. Thus, the dashed lines start on zero. During DOY 75, the maximum NmF2 shows the well-known two crests, which have different intensities and the location varies between $0^{\circ}$ and $25^{\circ}$ in latitude during the quiet day. Since the crest is parallel to the geomagnetic equator, the latitude of the crest presented in geographic coordinates in Figure 5 is changing with time. A very similar pattern occurs in DOY 76 until 14 hours UT. During the storm main phase, after 14 UT, the EIA crests clearly deviate poleward from its quiet time evolution as a result of the prolonged time with reduced values of the SYM/H index. The displacement of the EIA crests in the main phase suddenly increases after 14 hours UT, reaching a maximum displacement of $9^{\circ}$ in the Northern hemisphere at 17 hours UT (dashed red line) and a maximum displacement of $20^{\circ}$ in the Southern hemisphere at 18 hours UT (dashed blue line). This suggests the penetration of the eastward electric field in the daytime ionosphere, which increases the force driving the vertical drift of the fountain effect and changes the EIA configuration. Despite the higher displacement of the NmF2 peak at the South, the whole structure of the Northern crest is affected up to about $50^{\circ}$ in latitude (top panel). The storminduced disturbance on EIA continues severely affecting the Southern crest until $\sim 2$ hours UT of DOY 77. However, after two inflection points of the SYM/H index (9 UT and 23 UT in DOY

This article is protected by copyright. All rights reserved. 
76), the anomaly starts to be significantly suppressed with a sharp decrease in the displacement of the crests, reflecting a recovery phase. Since there are no evident EIA crests, the two crests of the $\mathrm{NmF} 2$ are merged into one. However, it is evident the overall capabilities of using such threedimensional reconstructions for a global analysis of the storm induced effects in the ionosphere. A still missing point to verify is related to the accuracy of the electron density estimation with the developed technique, which will be discussed in the next section.
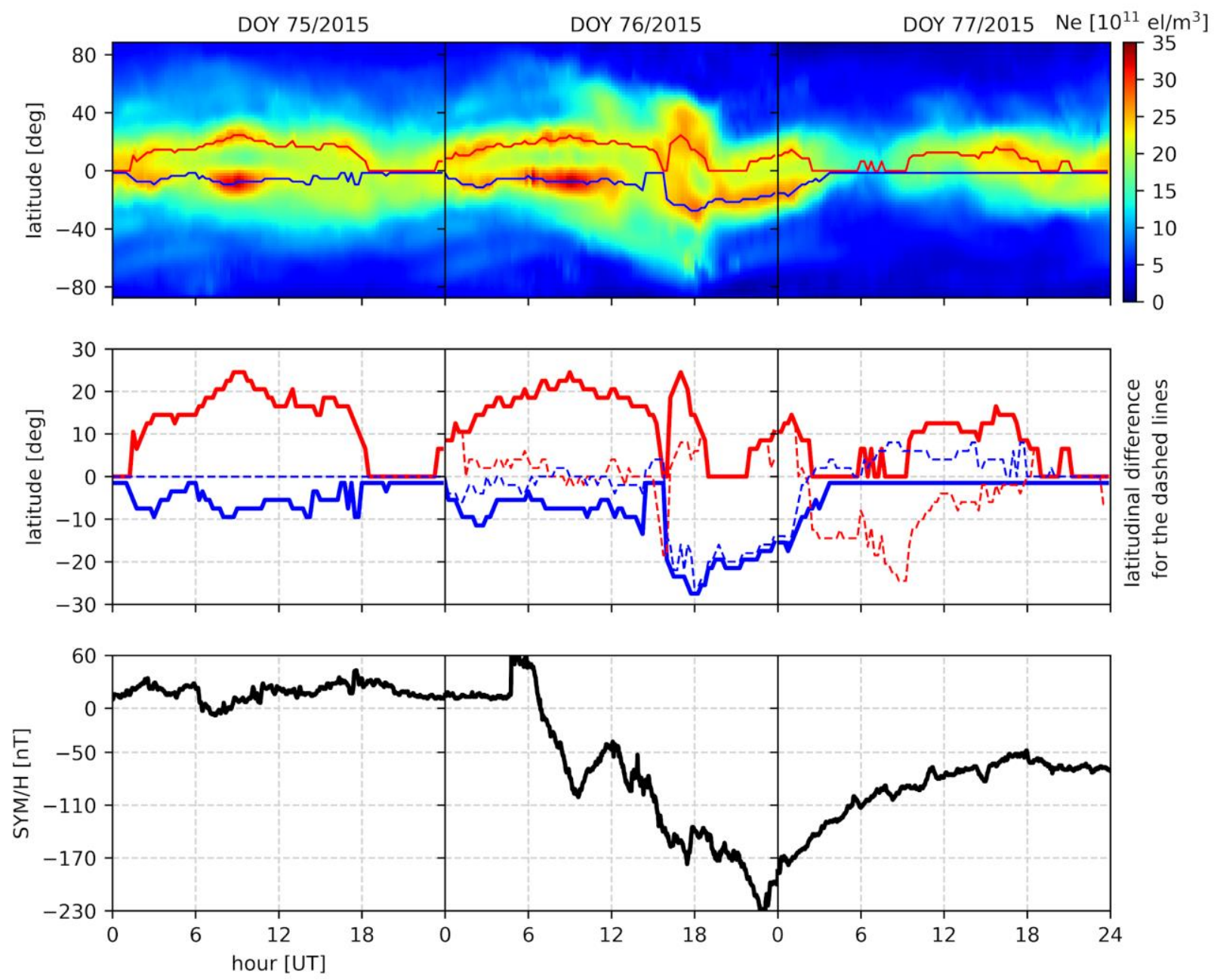

Figure 5. Top panel: peak of electron density $(\mathrm{NmF} 2)$ in terms of geographical latitude by universal time. The NmF2 values are estimated for a fixed time at 15 -hour LT. Blue and red lines represent the segmentation of the maximum $\mathrm{NmF} 2$ values at the EIA crests, showing the location of the latitudinal peak of NmF2; Middle panel: zoom at the segmented EIA peaks (solid lines) and its difference when compared to DOY 75 (dashed lines). Bottom panel: SYM/H index provided the Goddard Space Flight Center in the OMNI data set.

This article is protected by copyright. All rights reserved. 


\subsection{Electron Density comparison to observations and models}

The electron density assessment compares the tomography results with NEDM and TIEGCM. We chose NEDM (briefly described in Jakowski and Hoque, 2019) as a representative empirical model. The TIE-GCM was selected for this comparison since it is a well-established physics-based model (Hsu et al., 2021; Kodikara et al., 2021; Qian et al., 2014). TIE-GCM uses a finite differencing technique to discretize the numerical solutions for the conservation of mass, energy, and momentum to model the coupled ionosphere-thermosphere (Richmond et al., 1992; Qian et al., 2014). In this study, we use the TIE-GCM version 2.0 (released on 21 March 2016) with a model time-step of $30 \mathrm{~s}$. The website <http://www.hao.ucar.edu/modeling/tgcm > provides more details about the open-source TIE-GCM code. The TIE-GCM model configuration used in this study is as follows: horizontal resolution of $2.5^{\circ}$ in latitude and $2.5^{\circ}$ in longitude, vertical scale-height of 0.25 , solar irradiance input by the daily $F_{10.7}$ index and its running 81-day centered mean, high latitude electric potential by the Weimer et al. (2005) ion convection model, and lower atmospheric tidal forcing by the Hagan et al. (2001) global scale wave model. The model's vertical domain extends from approximately 97 to $600 \mathrm{~km}$ depending on solar activity. The model runs presented here also use the Qian et al. (2009) day-of-year dependent eddy diffusion coefficient to add perturbations to the advective and diffusive transport. In order to compare with different data products presented in this study, we linearly interpolate the TIEGCM estimates to the data location, first along the geographic latitude and longitude and then a logarithmic interpolation to the geometric height.

In order to evaluate the accuracy of the tomography electron density estimations in the peak height, Figure 6 shows the critical frequency (foF2) values retrieved by ionosondes, tomography, background NEDM, and TIE-GCM during the week of the St. Patrick's Day storm. Figure 7 shows a similar graph to Figure 6, but for the difference between the model results and the ionosonde data. Here 40 ionosondes are used to show the local time variations. Each latitude row in Figures 6 and 7 corresponds to a distinct ionosonde. As can be seen, the ionosonde data present typical distributions, such as higher ionization in low-latitudes at the daytime and lower foF2 values in mid-latitudes at the nighttime. In general, tomography reproduced the foF2 distributions well including storm signatures during DOY 76, which is mainly shown by electron density enhancements during the disturbed geomagnetic activity, and after $17 \mathrm{March}$, during the storm recovery phase. Tomography correctly reproduces the foF2 variations observed by the ionosondes with a small underestimation. The background NEDM remains relatively steady and hardly follows the observed foF2 variability. TIE-GCM is also capable of reproducing the foF2 enhancement and decrease in the main and recover phases, respectively. Indeed, TIE-GCM is driven with geophysical indices that represent the disturbed conditions. The bias in tomography range from -2 to $2 \mathrm{MHz}$, while bias in TIE-GCM (NEDM) is around 4 (3) MHz, mainly during the storm phase. A complete statistical view on the differences between the methods is presented in Table 1 .

This article is protected by copyright. All rights reserved. 


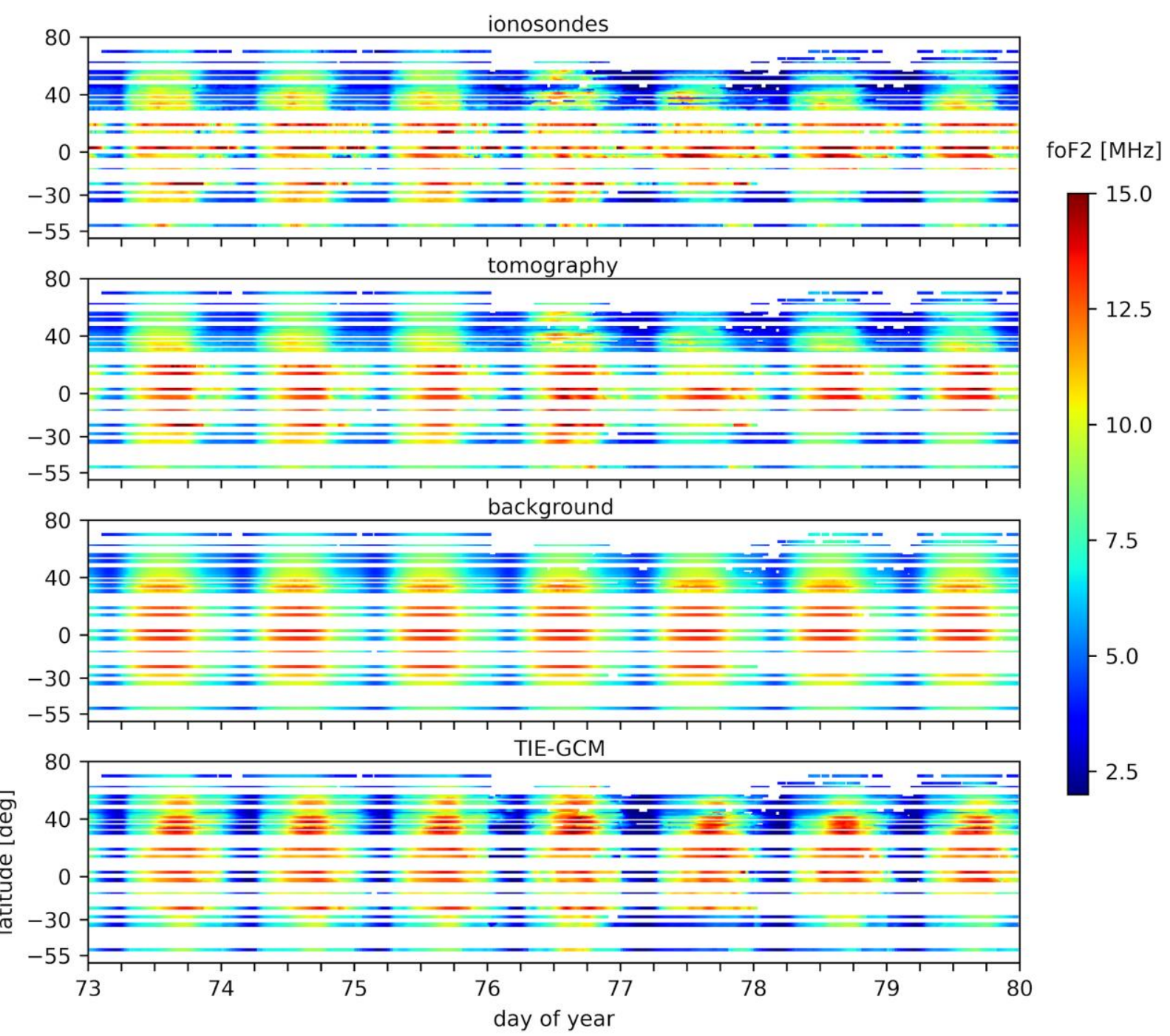

Figure 6. Critical frequency (foF2) values observed by ionosondes, tomography, background NEDM and TIE-GCM during 14-21 March 2015. Each latitude row corresponds to one ionosonde station. White spaces show the absence of data. The time resolution of the data is 15 minutes.

This article is protected by copyright. All rights reserved. 


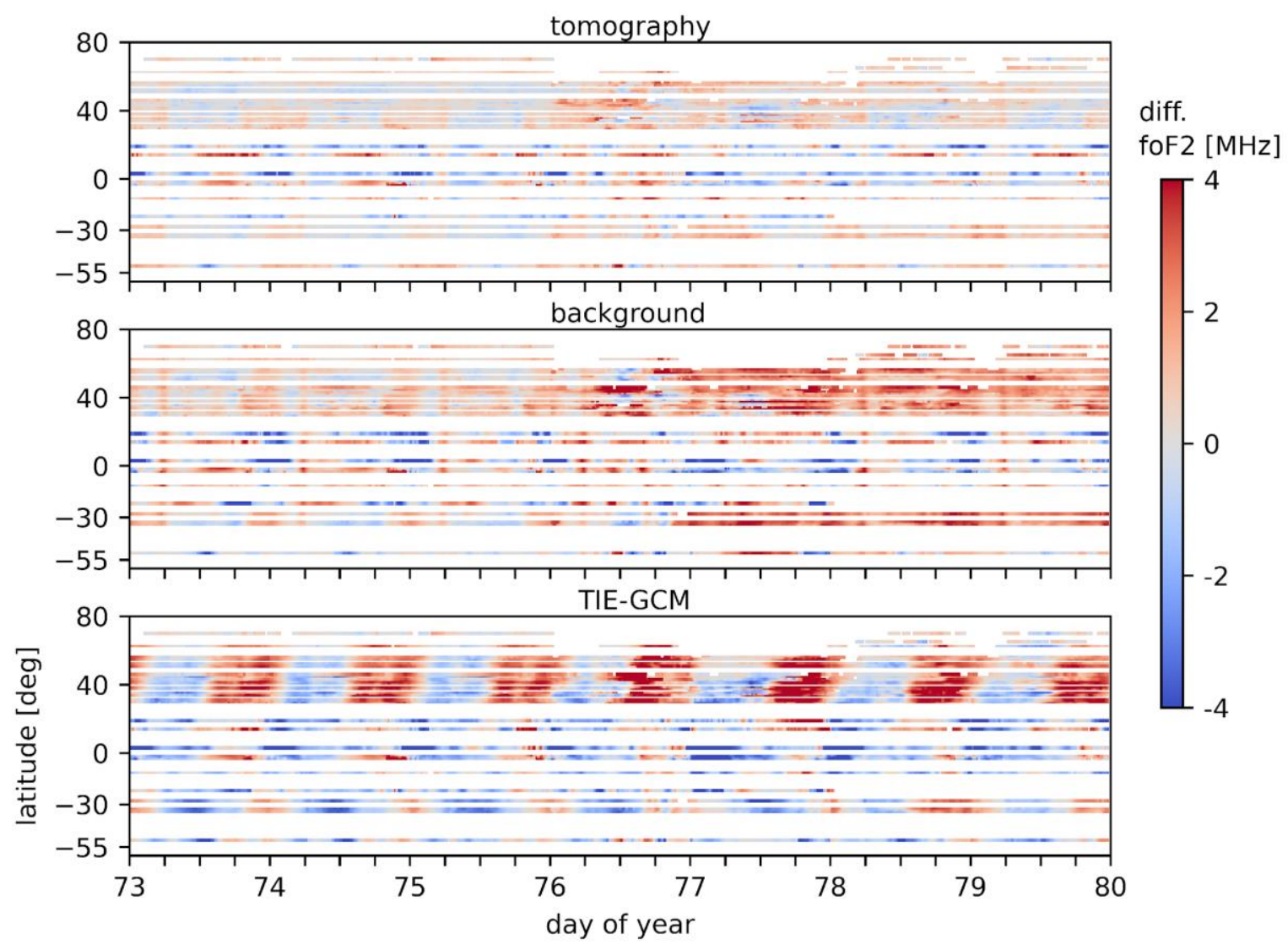

Figure 7. Difference in critical frequency (diff foF2) between ionosonde observations and tomography (upper panel), background NEDM (middle panel) and TIE-GCM (bottom panel).

In order to assess the tomography capabilities in reproducing the electron density distribution at altitudes above the peak height, in-situ electron density measurements from GRACE, Swarm and DMSP satellites are used as reference. For each instrument, we discriminate the in-situ measurements in two geometries, referred to as rising and setting phases. The rising phase is referred to when the satellite is flying from the South to North direction, while the setting phase is related from the North to South direction. In the presented experiments, the rising phase of GRACE and Swarm occur during the daytime, around 18 LT in the equatorial region. The rising phase of DMSP occurs during the nighttime, around $2 \mathrm{LT}$ in the equatorial region. The setting phases in the equatorial region occur around 06 LT for GRACE and SWARM satellites, and around 14 LT for DMSP. Figures 8, 9 and 10 show the in-situ measurements of GRACE, Swarm and DMSP, respectively, for the week of interest as well as the corresponding tomography, background and TIE-GCM estimations. TIE-GCM is not compared with DMSP due to the model's limited vertical domain. The electron density distributions are estimated by the models along the trajectories of the satellites.

This article is protected by copyright. All rights reserved. 


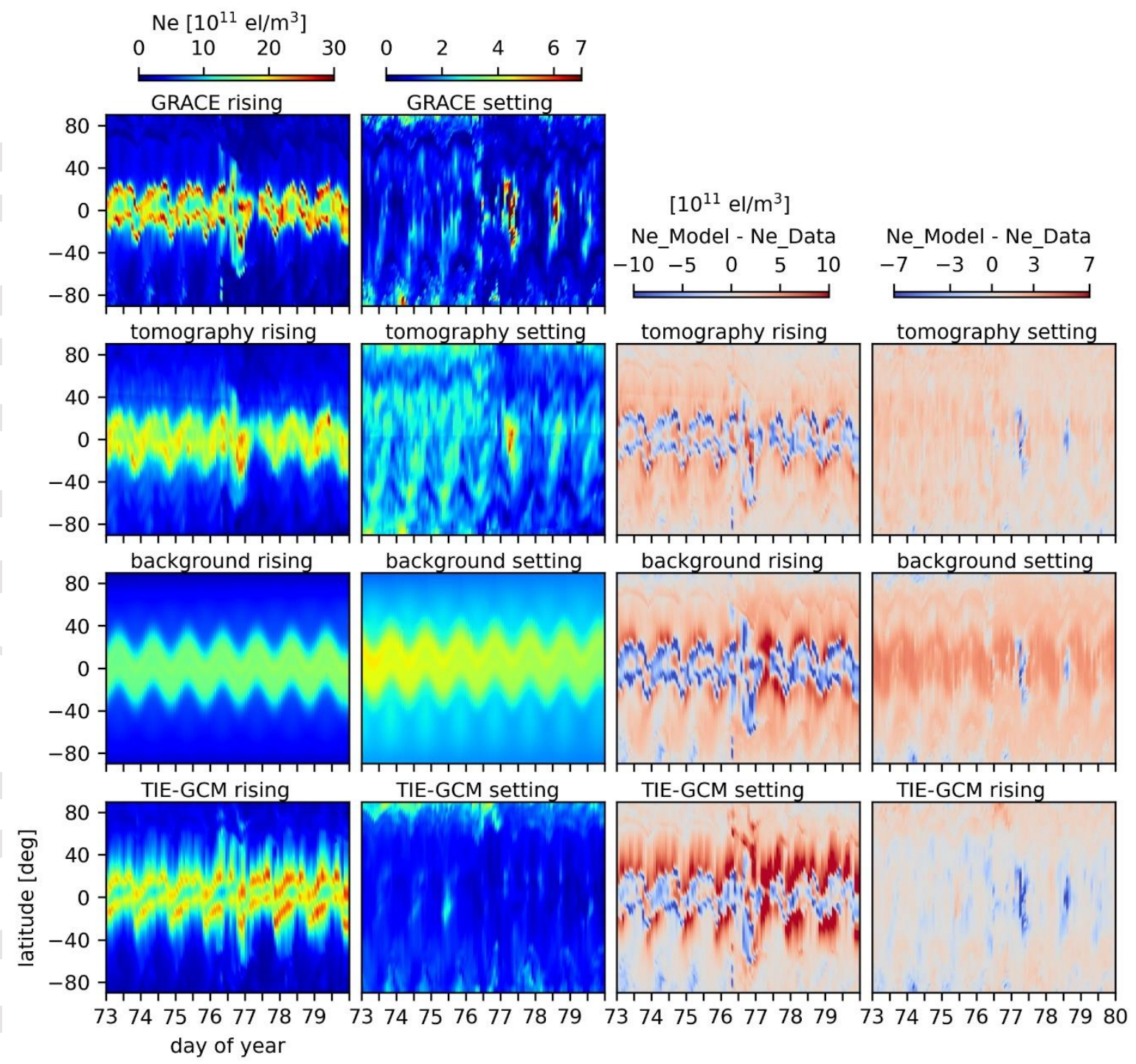

Figure 8. Two left columns: Electron density distributions during the week of the St. Patrick storm, 2015, obtained with in-situ measurements of the GRACE satellite. Tomography, background NEDM and TIE-GCM results are shown in the bottom panels. The electron density throughout the week was estimated in terms of local time. Two right columns: Discrepancies between model and data values. In all cases, the electron density distributions are shown along the trajectories of the satellites.

This article is protected by copyright. All rights reserved. 


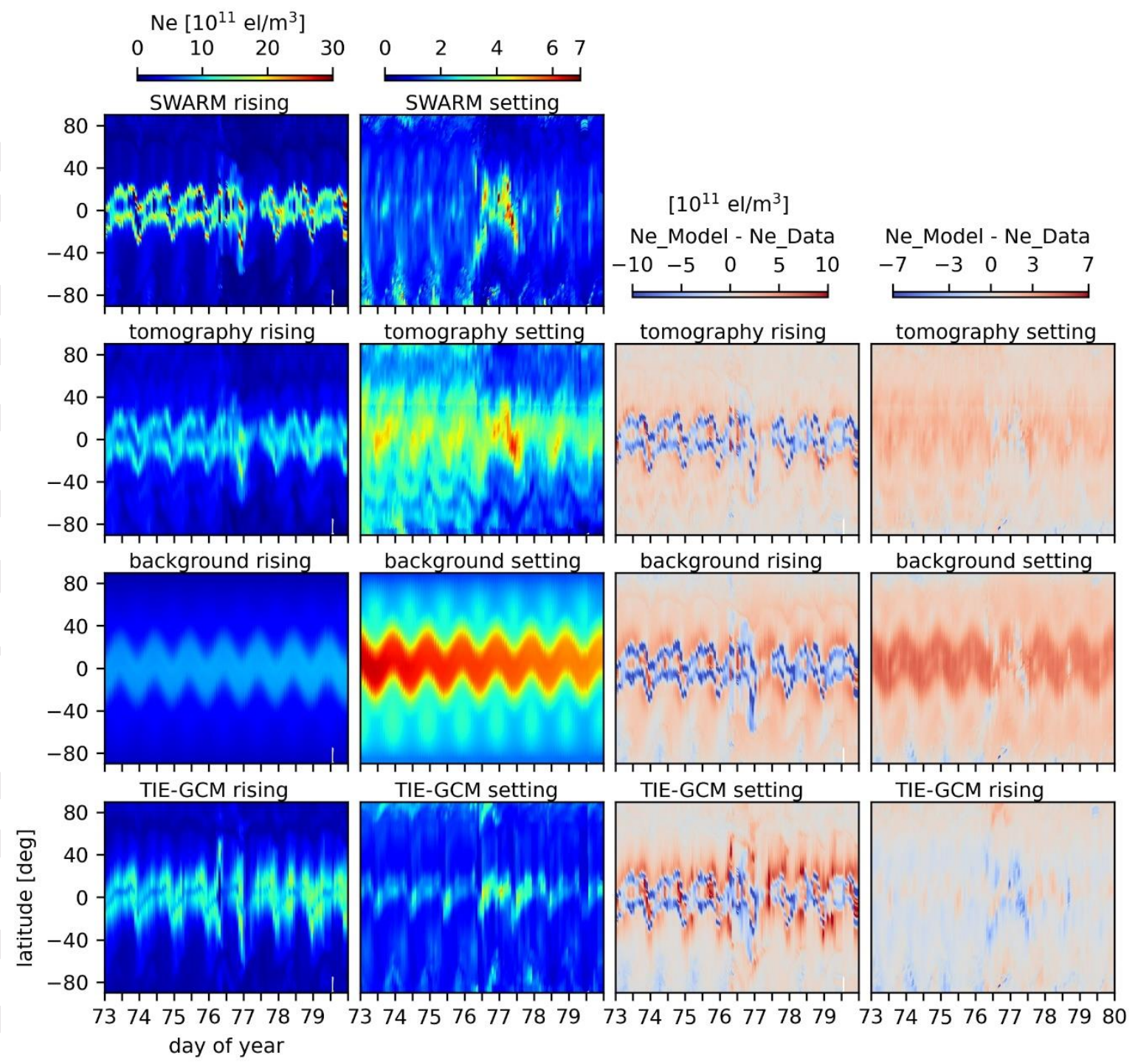

Figure 9. Same as Figure 8 but for Swarm-A satellite.

Assessing Figures 8 and 9, we can see two crests in the daytime equatorial region at the GRACE and Swarm altitudes, likely associated with the influence of the fountain effect. During the DOY 76, the main phase of the storm has contributed to an enhancement of electron density. Additionally, due to the disturbed geomagnetic fields, we can see a slight change in the EIA structure in DOY 76 in comparison to other DOYs. Although the background NEDM has not shown such variabilities in the daytime, the tomography and TIE-GCM show plasma enhancements around the equator but slightly less than as measured by GRACE and Swarm. During nighttime, low electron densities were observed for GRACE and Swarm. As shown in Figures 8 and 9, the tomography correctly maps the Ne enhancements in the equatorial region during the setting phase of both GRACE and Swarm on DOYs 76 through 78. A general overestimation from tomography is observed at nighttime. Overall, TIE-GCM corresponds well with GRACE and Swarm measurements; however, in Figure 8, TIE-GCM does not seem to capture the plasma enhancement in the low latitudes on DOYs 78 and 79 during nighttime.

This article is protected by copyright. All rights reserved. 
Swarm and TIE-GCM also show such enhancement during this nighttime period in Figure 9 but the TIE-GCM results are slightly different in intensity and spatial distribution. In case of the DMSP results, we have observed a better representation of the electron density by tomography in comparison to the background NEDM, being capable to show more correlated distributions as well as storm signatures in the electron density, such as the electron density enhancement during DOY 76 in the rising phase (nighttime). However, in the discrepancy level, NEDM and tomography provide very similar results.

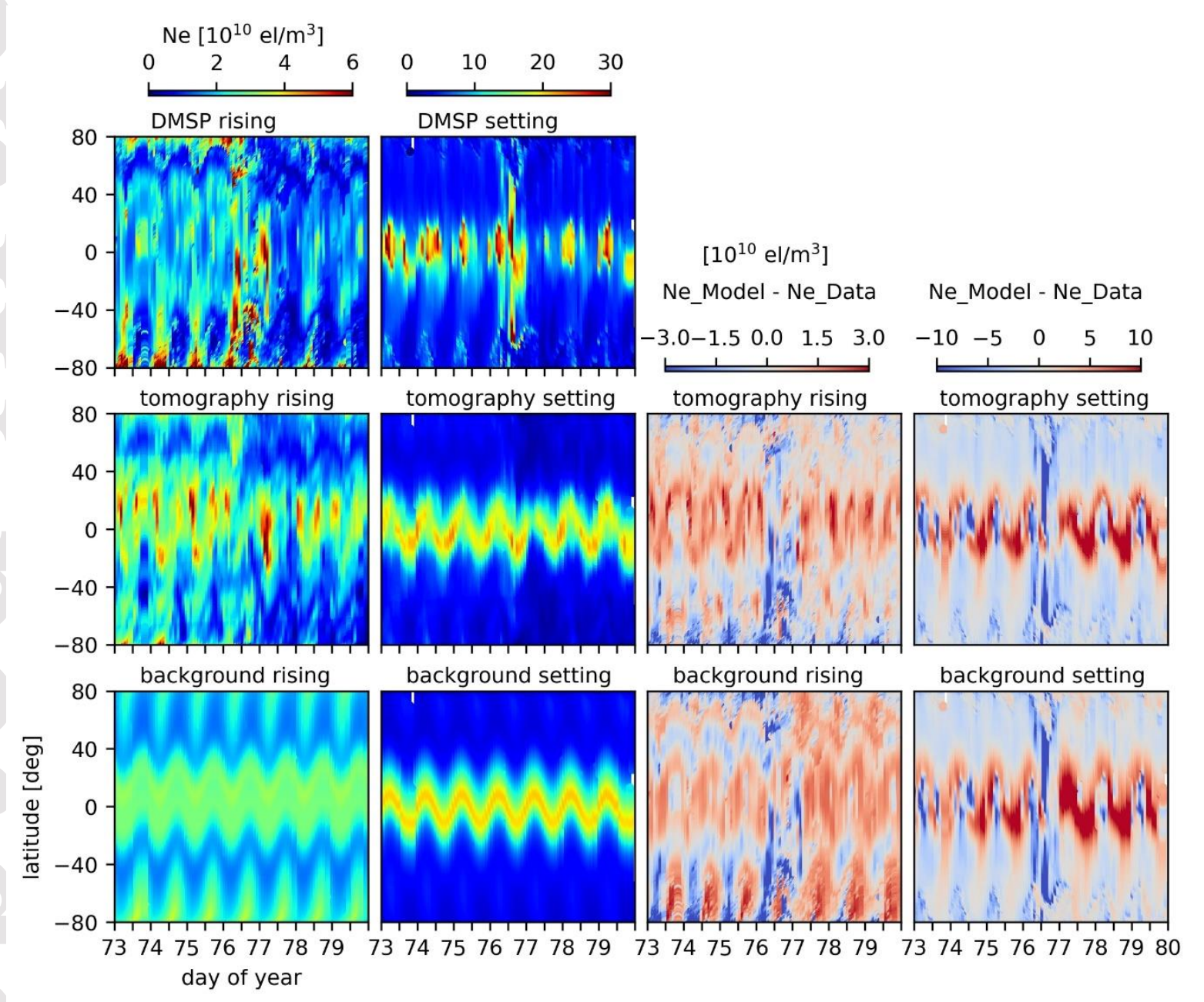

Figure 10. Same as Figure 8 but for DMSP-F15 satellite.

In order to show the tomography performance to represent electron density profiles, specific cases of the ISR instrument at Millstone Hill were used as reference. Figure 11 shows four representative examples of the electron density profiles seen by tomography, the background NEDM model and TIE-GCM. The first three columns show the electron density profiles at 19 UT (10.4 LT), when the electron density was considerably disturbed during DOYs 76, 77 and 78. Unfortunately, no data was recorded before DOY 76. Results at DOY 79/19 UT are equal to DOY 78 at 19 UT, so that the fourth column is provided as an example to show the profile estimation at a distinct hour of DOY 79. We chose an hour in the nighttime (21.6 LT) to show an example of a profile at DOY 79. In most cases, the tomography results show lowest

This article is protected by copyright. All rights reserved. 
deviation from the ISR measurements. In contrast, the deviations between the models (NEDM and TIE-GCM) are varying a lot. During the recovery days of 77, 78 and 79, tomography reproduced well the ISR electron density profiles. During DOY 76, the tomography profile is also closer to the ISR data than the models, but attention has to be paid to significant deviations from ISR measurements in altitudes below $350 \mathrm{~km}$. During the storm day (DOY 76), the ISR data profile is uplifted in comparison to modeling profiles. Neither the background NEDM and tomography were capable of showing such vertical distribution. However, in any case, tomography has presented a better agreement in the electron density profile estimations. With regard to TIE-GCM, we observe a strong overestimation in the example of DOYs 76 and 79. In a few cases of the recovery phase (DOY 77), we observe that TIE-GCM to show best consistency with ISR data, overpassing the tomography performance. The background was in general quite far from the observed profile.

A broader comparison of the electron density profiles of the ISR instrument at Millstone Hill is shown in Figure 12. We have neglected the data of DOY 76 in this example since very few electron density measurements were collected in DOY 76, in such a way that we could not observe the daily evolution of electron density distributions. Overall, we can confirm the analysis made in the examples of Figure 11, in which tomography has clearly outperformed the background NEDM and TIE-GCM.

Table 1 shows a statistical overview of the tomography performance in comparison to the background and TIE-GCM in terms of the average of the error (model - data), standard-deviation of the error, and percentage of the Pearson correlation coefficient between model and data. The average error was computed using the experimental data set of all measurements available in the period of interest from the ionosondes, GRACE, Swarm, DMSP, and ISR. A positive average error stands for an overestimation, while negative averages indicate underestimations. Overall, we can see a significant improvement of tomography in comparison to the background for all the instruments, in the average, standard deviation and correlation. The percentage of improvement considering the root mean square error (RMSE) was $45 \%, 31 \%, 30 \%, 7 \%$ and $55 \%$, for ionosonde, GRACE, Swarm, DMSP, and ISR, respectively. There is no relevant improvement in the DMSP assessment because NEDM was developed using DMSP in-situ measurements to calibrate the topside model. The physics-based TIE-GCM shows the lowest error for GRACE and Swarm. However, the standard deviation for the same cases is larger than for the tomography results. Based on the analysis of Figures 8 and 9, we assume that the correct representation of the electron density magnitude for GRACE and Swarm, with no relevant under or overestimations, was the main reason TIE-GCM presents lower average errors in comparison to tomography. However, the TIE-GCM error dispersion and correlation is larger.

This article is protected by copyright. All rights reserved. 


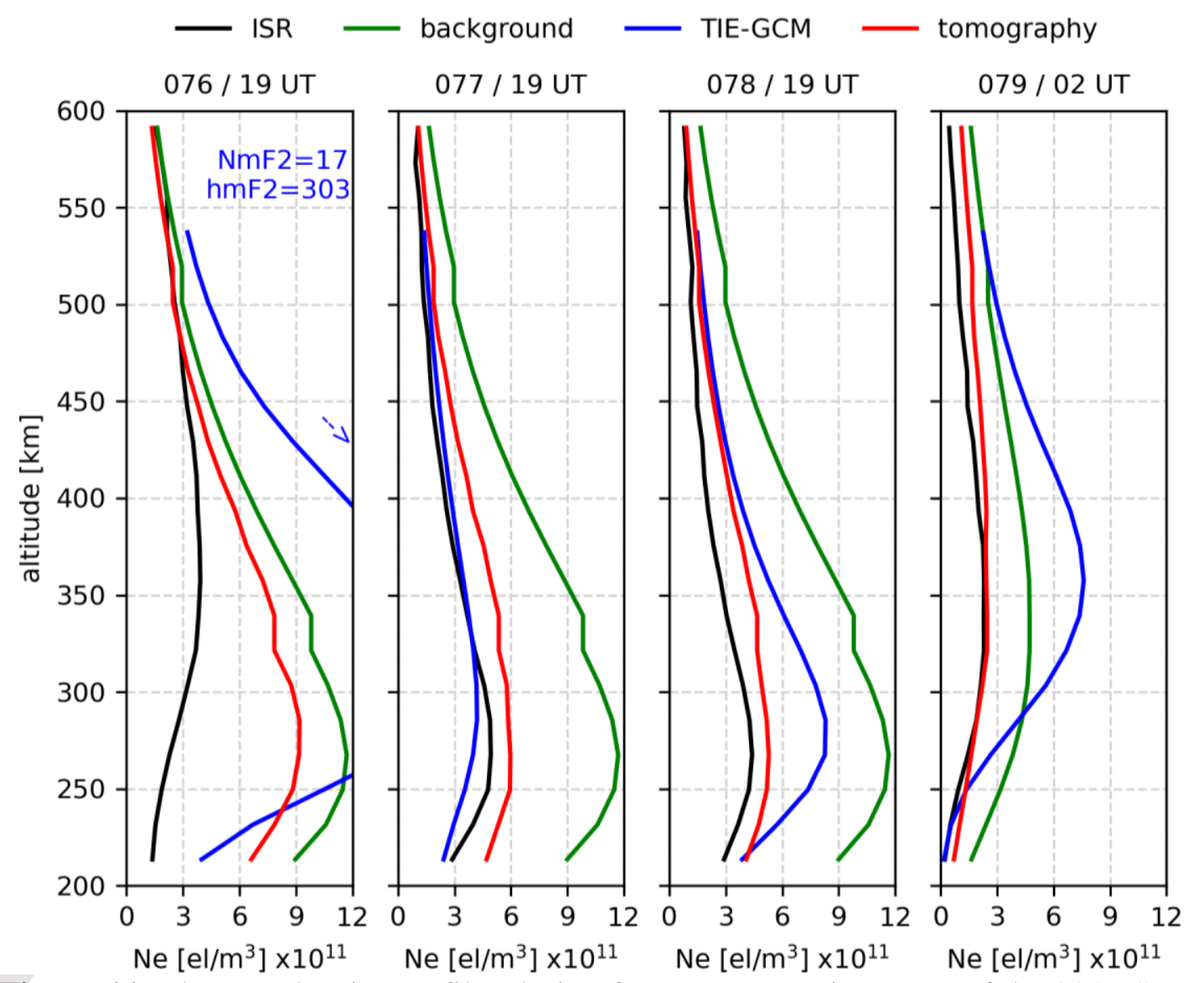

Figure 11. Electron density profiles during four representative cases of the 2015 St. Patrick Day obtained by ISR measurements $\left(42^{\circ} 37^{\prime} \mathrm{N}, 71^{\circ} 29^{\prime} \mathrm{W}\right)$, tomography, background and TIE-GCM.

Table 1. Mean $(\mu)$ and standard-deviation $(\sigma)$ of the model-data difference for tomography (TOMO), background NEDM, and TIE-GCM. Last three columns provide the respective Pearson correlation coefficients as a percentage $(r)$.

\begin{tabular}{c|ccccccccc}
\hline \multicolumn{1}{c}{ respective Pearson correlation coefficients as a percentage $(r)$. } \\
\hline Data & $\mu^{\text {TOMO }}$ & $\mu^{\text {NEDM }}$ & $\mu^{\text {TIEGCM }}$ & $\sigma^{\text {TOMO }}$ & $\sigma^{\text {NEDM }}$ & $\sigma^{\text {TIEGCM }}$ & $r^{\text {TOMO }}$ & $r^{\text {NEDM }}$ & $r^{\text {TIEGCM }}$ \\
\hline Ionosonde foF2 $[\mathrm{MHz}]$ & 0.13 & 0.93 & 0.62 & 1.05 & 1.69 & 2.42 & $91.4 \%$ & $79.6 \%$ & $65.9 \%$ \\
GRACE Ne $\left[10^{11} \mathrm{el} / \mathrm{m}^{3}\right]$ & 1.10 & 1.43 & 1.03 & 1.98 & 2.96 & 3.08 & $93.4 \%$ & $85.1 \%$ & $84.9 \%$ \\
Swarm Ne $\left[10^{11} \mathrm{el} / \mathrm{m}^{3}\right]$ & 0.85 & 1.31 & 0.43 & 1.86 & 2.64 & 2.27 & $86.6 \%$ & $66.7 \%$ & $77.4 \%$ \\
DMSP Ne $\left[10^{11} \mathrm{el} / \mathrm{m}^{3}\right]$ & -0.01 & 0.01 & - & 0.31 & 0.34 & - & $74.9 \%$ & $70.7 \%$ & - \\
ISR Ne $\left[10^{11} \mathrm{el} / \mathrm{m}^{3}\right]$ & 1.09 & 3.01 & 1.79 & 1.23 & 2.09 & 2.88 & $84.4 \%$ & $55.5 \%$ & $77.2 \%$ \\
\hline Total Mean & 0.64 & 1.34 & 0.97 & 1.29 & 1.94 & 2.66 & $86.1 \%$ & $71.5 \%$ & $76.3 \%$ \\
\hline
\end{tabular}

This article is protected by copyright. All rights reserved. 

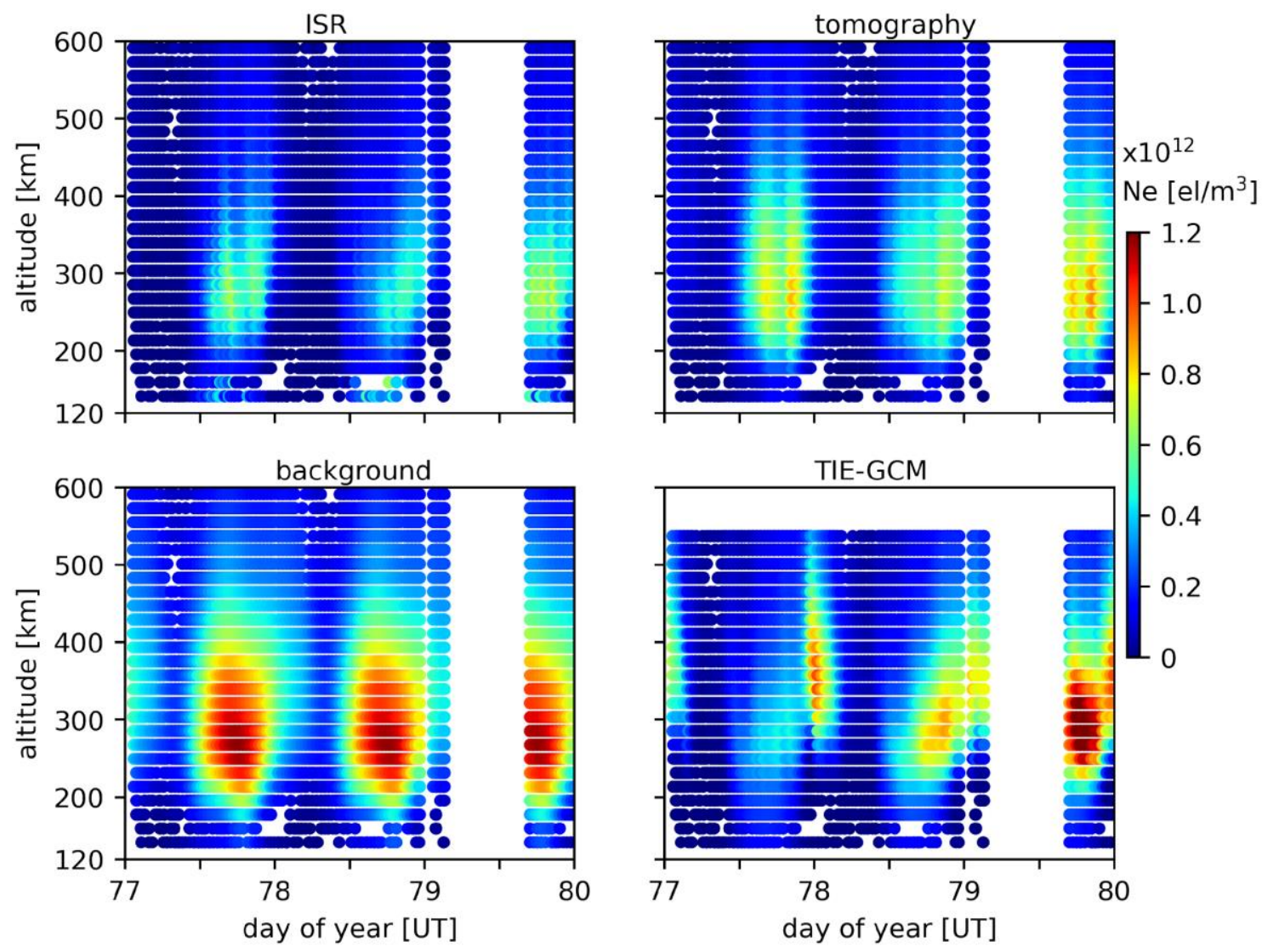

Figure 12. Electron density profiles obtained by ISR measurements $\left(42^{\circ} 37^{\prime} \mathrm{N}, 71^{\circ} 29^{\prime} \mathrm{W}\right)$, tomography, background and TIE-GCM.

\section{Discussion}

In this work, we present a global 3D reconstruction of the ionosphere electron density capable of reproducing challenging conditions during ionosphere storms. One of the most recent advances in this field has been presented by Cheng et al. (2021). Although the objective of our work equals Cheng et al. (2021), the implementation and capabilities of the CIT studies differ. The spatial resolution of the tomography result presented here is $2^{\circ} \times 2^{\circ} \times 20 \mathrm{~km}$ for latitude, longitude, and altitude respectively, covering from 50 to $20,000 \mathrm{~km}$ in altitude with a temporal resolution of 15 minutes. According to the authors' knowledge, this work presents the highest resolution of global CIT to date. Our method also incorporates more GNSS receivers and utilizes optimized constraints on the reconstruction. While the number of used ionosphere measurements is significantly lower in Cheng et al. (2021), they have the advantage of data coverage also over the oceans, because they are not only using combined multi-GNSS (GPS, GLONASS, BDS, and Galileo) observations, but also radio occultation (RO) measurements from Constellation Observing System for Meteorology, Ionosphere, and Climate (COSMIC) satellites. Although more data and a higher spatial and temporal resolution is applied in the study presented here, the computation of the CIT still completes within 20 to 30 minutes. This computational time is close to Cheng et al. (2021) who achieve 10 minutes computation time. There is still room for improvements in our processing time since we have used a simple computer with no parallel

This article is protected by copyright. All rights reserved. 
computing. The processing machine uses a socket of six intel $i 7$ cores from the $9^{\text {th }}$ generation with $16 \mathrm{~Gb}$ of memory RAM.

The capability of the applied CIT to reproduce ionosphere storm conditions is assessed based on the example of the St. Patrick's Day storm 2015 and discussed here with respect to published ionosphere storm studies for this event. E.g. Nava et al. (2016) describe that at the beginning of the storm, one or two periods of enhanced ionization with respect to quiet times (positive storm effects) were observed depending on the longitudinal zones. The authors showed that the American region exhibits the most remarkable increase in vertical total electron content (VTEC). Furthermore, a strong decrease in ionization (negative storm) is observed at all longitudes after the main phase of the storm, lasting several days (e.g. Nava et al., 2016, Fagundes et al., 2016). This decrease was reported to be the largest in the Asian sector. The remarkable ionization increase in the American region and a strong decrease in the Asian sector are also confirmed in the present work at Figure 2 at 18 hours UT in DOY 76 (America) and at 6 UT in DOY 77 (Asia).

The CIT results presented here indicate a hemispheric asymmetry of the ionosphere storm perturbations. In Figs. 3 and 4, a larger plasma density enhancement has been shown in the Northern hemisphere compared to the Southern hemisphere, especially after 18 UT. This effect, with dependency on the longitudinal sector, has been discussed by Astafyeva et al. (2015). They explain this effect with composition changes and partly with the different non-dipolar portions of the geomagnetic field in the two hemispheres as well as with IMF By component variations. In addition, Liu et al. (2016) reported a hemispheric asymmetry also in the negative storm conditions close to the storm enhanced density on DOY 76, where the Northern hemisphere negative storm was stronger than in the Southern hemisphere. This effect is visible in Figure 3 (second panel row from the bottom).

In section 4.1, special attention has been paid to the presentation of the EIA. The EIA is developed because the electric and magnetic fields are, in general, perpendicular to each other over the geomagnetic equator in the ionosphere. The resulting force in the daytime drives the electron density to higher altitudes with a drift velocity $\mathrm{E} \times \mathrm{B}$, where $\mathrm{E}$ and $\mathrm{B}$ are the electric and geomagnetic field vectors (Anderson 1981). As described in Prol et al. (2018c), the peak height and the whole profile distribution are proportionally uplifted depending on the intensity of the zonal electric fields at the equator. At higher altitudes, the uplifted plasma diffuses along with the geomagnetic field lines as a consequence of the pressure and gravity forces. The plasma diffusion along the geomagnetic field lines creates two crests at about $15^{\circ}$ to the North and South. The two crests formed by the so-called fountain effect can be clearly observed in Figures 2 and 3 . The EIA crests in DOY 75 represents a natural development during quiet times, showing daily variabilities due to the expected longitudinal asymmetries, which can be related to daily variations of the solar ionization, longitudinal differences of the zonal electric field and distinct ionization level due to the geomagnetic field configuration (Kil et al., 2011). In addition, we have observed that the EIA crests at DOY 76 after 14 UT have a higher ionization level and are more far apart than during the quiet and recovery days (Figs. 3-5). These features also agree well with the observations of the superfountain (e.g. Nayak et al., 2016, Fagundes et al., 2016). Based on the electron density reconstructions, we could observe a displacement of the EIA crests induced by the storm by $9^{\circ}$ to $20^{\circ}$ in latitude when compared to a quiet day. This effect relates to the penetration of an eastward electric field in the daytime ionosphere, as described by e.g. Hairston et al. (2016). This electric field increases the force driving the vertical drift of the

This article is protected by copyright. All rights reserved. 
fountain effect and changes the EIA configuration. Also, several other studies of the St. Patrick's Day storm 2015 (e.g., Astafyeva et al., 2015; Fagundes et al., 2016; Yue et al., 2016; Nayak et al., 2016; Liu et al., 2016; Huba et al., 2017) suggest the involvement of eastward penetration electric fields not only in the EIA enhancement but also more general in the electron density enhancements in the ionosphere during the main storm phase.

A significant decrease in the EIA intensity has been shown in Figure 5, starting at 2 UT on DOY 77 a few hours after the storm recovery started. A complete reversal in the longitudinal structure/pattern of EIA during the recovery phase of the storm as compared to the quiet day has been reported by Yadav et al. (2016). Also, in mid-latitudes, a strong negative storm is apparently visible in Figs. 2 and 5. As shown by Yadav et al. (2016) and Borries et al. (2016), the suppression of EIA can be associated with the Disturbance Dynamo Electric Field (DDEF) and westward PPEF due to a northward turning point of the Bz component in the interplanetary magnetic field. A resulting counter equatorial electrojet (CEJ) imposes the westward electric field over the daytime ionosphere and generates a depression of TEC and EIA around 6-12 UT. In addition, a short partial recovery phase has been reported during 9 to 12 UT (e.g. Yadav et al., 2016, Borries et al., 2016), which is associated with reduced TEC enhancements with a certain delay to this period. A slight decrease in the intensity of the EIA on DOY 76 between 12 and 14 UT, visible in Figure 5, can be associated to this partial recovery phase. During the partial recovery phase a westward PPEF due to a northward turning point of the Bz component in the interplanetary magnetic field is suggested in Yadav et al. (2016) and Borries et al. (2016). A resulting counter equatorial electrojet (CEJ) imposes the westward electric field over the daytime ionosphere and generates a depression of TEC and EIA.

A significantly higher $\mathrm{F} 2$-layer peak height $(\mathrm{hmF} 2)$ has been detected by the Millstone Hill ISR (Figure 11). Liu et al. (2016), who analyzed the Millstone Hill data in more detail, point out that while TEC was enhanced, a decrease in $\mathrm{NmF} 2$ and an increase in hmF2 took place. The plasma was distributed over a much larger range of altitude. An increase of the density of molecular neutrals, resulting in enhanced recombination, is responsible for the observed decrease in NmF2. These hmF2 changes during storm conditions can be caused by zonal electric fields and meridional thermosphere winds. Zhang et al. (2017b) describe the contribution of the PPEF to the upward and poleward plasma transport for the Millstone Hill observatory in the association with the storm enhanced density during the St. Patrick's Day storm 2015. Also, Ratovsky et al. (2021) identify the zonal electric field as the main contributor to the hmF2 increase over the Irkutsk station during the St. Patrick's Days storm 2015. Figure 11 shows a limited capability of the tomography result to reproduce the hmF2 increase. This is mainly associated with the limitations of the background model and the complex electrodynamic processes generating this effect. Indeed, the developed tomography is highly dependent on the hmF2 values of the background. The background NEDM hmF2 was not capable of showing such vertical distribution, which is reflected in the tomography performance.

An extensive model-data comparison has been presented in section 4.2, using ionosonde, incoherent scatter radar, Swarm, GRACE and DMSP electron density data. It has been shown that the tomography approach generates very good estimations of the $3 \mathrm{D}$ electron density and can provide improvements in comparison to NEDM and the numerical model TIE-GCM (lower RMSE and better correlation coefficients than the numerical model). The larger standard deviation of TIE-GCM is justified since an overall larger structure of the EIA was reproduced by TIE-GCM during the satellite's rising phase. After the storm onset, during DOY 76, higher

This article is protected by copyright. All rights reserved. 
electron densities are reproduced by TIE-GCM above \pm 40 degrees in latitude, while the reference data and tomography are more concentrated to the low-latitudes. In terms of RMSE, tomography outperforms TIE-GCM by $57 \%, 30 \%, 11 \%$, and $51 \%$ for ionosonde, GRACE, Swarm, and ISR data, respectively. However, there is still some potential for improvement, since some error estimates in Table 1 (bias with respect to GRACE and Swarm electron densities) are smaller for TIE-GCM than for the CIT result. Also, an overestimation of tomography electron densities above the peak height (measured with GRACE and Swarm, Figures 8 and 9) has been identified, which is expected to be a consequence of the even larger overestimation of the background NEDM. This shows that even after the tomographic update, there is still an important dependence on the background to regularize the solution. In greater altitudes, the error of the tomography results become rather small (Figs. 10 to 12 and Table 1). Still, there is room for improvement at greater altitudes since the electron density magnitude during the DMSP setting phase is underestimated by the tomography. For instance, in Figure 10, tomography was not capable of reproducing the DMSP electron density storm enhancement over a wide range of latitudes in DOY 77. Analyzing the dataset, it is plausible that this discrepancy may be due to the lack of GNSS data over the oceans. Indeed, over the oceans, the tomography performance mainly relies on the background and the CODE VTEC maps. A dedicated study may still be necessary to understand the performance of the tomography in these regions. Incorporation of radio-occultation-derived electron density in the tomography may help to improve the specification over larger areas. As discussed by Cheng et al. (2021), GNSS radio-occultation techniques can overcome the coverage limitation in ocean regions. Previous results, such as Prol et al., 2021, have presented a high correlation between DMSP electron densities and tomography using podTEC data, i.e., topside TEC measurements by GNSS receivers onboard LEO satellites. Therefore, additional TEC data observed by the precise orbit determination (POD) could also improve the tomography estimations to fill the data gaps.

It remains to assess the capabilities of the developed tomography for distinct ionospheric responses to the storm event other than the ones discussed above. The large-scale effects like the ionosphere trough, BPD, large-scale TIDs and the TOI, reported for this event (c.f. Sec. 3), should be visible in the presented global tomography results. The amplitudes of the large-scale TIDs are rather small compared to other storm perturbations (e.g. trough and BPD) and unlikely to be present in our tomography. Still, Bolmgren et al. (2020) demonstrated that a 3D reconstruction of large-scale TID signatures is possible with tomography. A detailed discussion of all these large-scale storm effects is beyond the ambit of this study. Additional studies are necessary to assess the capabilities of the presented tomography with respect to these large-scale storm effects. There exists a high interest, to also study finer ionosphere perturbation structures with CIT reconstructions. For example, plasma bubbles are shown to be visible in regional highresolution tomography results, as shown by Prol et al. (2018a) and medium-scale TIDs have been reconstructed with tomography by Chen et al. (2016). However, such effects cannot be discussed with the presented global tomography result, since the spatial resolution is not sufficient. In future work, it may be beneficial to investigate the performance and efficiency of the global tomography in comparison to regional reconstructions using dense GNSS networks, such as the regional methods applied over Japan (Saito et al. 2017). Data assimilation approaches applied on numerical models (e.g., Hsu et al., 2021; Kodikara et al., 2021) would also be an interesting option for comparison with the global-scale tomography results. Similarly, the high accuracy tomography outputs could be used to drive the numerical models in forecasting applications.

This article is protected by copyright. All rights reserved. 


\section{Conclusions}

This study demonstrated improved capabilities in quality and performance of tomographic techniques to obtain reliable electron density profiles during the analyzed geomagnetic storm using large data sets of TEC estimates derived from ground-based GNSS receivers. Improved temporal and spatial resolution for global electron density reconstructions can be achieved in the reconstruction. To test the method, a global network of ionosondes, as well as ISR observations and in-situ measurements of DMSP, GRACE, and Swarm are used. The results indicate the inversion scheme as a capable method to improve the accuracy of the background specifications and common models. Additionally, many physical mechanisms of the observed ionospheric disturbances have been discussed, showing the capabilities of the CIT technique to reconstruct the EIA and electron density signatures during disturbed conditions. The electron density reconstructions show well the displacement of the EIA crests compared to a quiet day, which is associated with a PPEF effect during the storm event. We also observed a significant inhibition of the EIA formation in the recovery phase, associated with a DDEF in the daytime. Also positive and negative storm effects and hemispheric differences are captured with the CIT reconstruction. Changes in the F2-layer peak height are not yet captured sufficiently. Future research is still required to improve the temporal and spatial resolutions of the reconstructions to detect finer structures, such as equatorial plasma bubbles and travelling ionospheric disturbances. Further analysis should be conducted to evaluate the global tomography during longer periods in order to analyze the model accuracy in different seasons and solar activities. However, the overall capabilities of using such three-dimensional reconstructions for a global analysis of the storm induced effects in the ionosphere are evident.

\section{Acknowledgments, Samples, and Data}

The authors would like to thank the continuously operating GNSS networks of Africa (AFREF - http://afrefdata.org/), South Africa (TrigNet - http://www.trignet.co.za/), Argentina (RAMSAC - Piñón et al., 2018), Australia (https://gnss.ga.gov.au/), Brazil (RBMC https://ibge.gov.br/), Europe (EUREF - https://www.epncb.oma.be/), United States (NOAA https://geodesy.noaa.gov/), and IGS (https://www.igs.org/). The GIRO datasets were downloaded from http://giro.uml.edu/. The authors also like to thank the providers of the following datasets: DMSP and ISR data from Millstone Hill (http://cedar.openmadrigal.org/), GRACE (https://www.gfz-potsdam.de/en/grace/), and Swarm (https://swarm-diss.eo.esa.int/). The National Center for Atmospheric Research, Colorado is acknowledged for making the TIE-GCM freely available at www.hao.ucar.edu/modeling/tgcm. This work was funded by the Deutsche Forschungsgemeinschaft (DFG) under the grant no. HO 6136/1-1 and by the 'Helmholtz Pilot Projects Information \& Data Science II' (grant support from the Initiative and Networking Fund of the Hermann von Helmholtz-Association Deutscher Forschungszentren e.V. (ZT-I-0022)) with the project named 'MAchine learning based Plasma density model' (MAP).

\section{References}

Anderson, D. N. (1981), Modeling the ambient, low latitude F-region ionosphere - a review. $J$ Atmos. Sol. Terr. Phys., 43, 753-762. doi:10.1016/0021-9169(81)90051-9.

Astafyeva, E., Zakharenkova, I., \& Förster, M. (2015), Ionospheric response to the 2015 St. Patrick's Day storm: A global multi-instrumental overview. J. Geophys. Res. Space Physics, 120, 9023-9037. doi:10.1002/2015JA021629

This article is protected by copyright. All rights reserved. 
Austen, J. R., Franke, S. J., \& Liu, C.H. (1988), Ionospheric imaging using computerized tomography. Radio Sci., 23, 299-307. doi:10.1029/RS023i003p00299

Bolmgren, K., Mitchell, C., Bruno, J., \& Bust, G. S. (2020), Tomographic imaging of traveling ionospheric disturbances using GNSS and geo stationary satellite observations. J. Geophys. Res. Space Physics, 125, e2019JA027551. doi:10.1029/2019JA027551

Borries, C., Mahrous, A. M., Ellahouny, N. M., \& Badeke R. (2016), Multiple ionospheric perturbations during the Saint Patrick's Day storm 2015 in the European-African sector. $J$. Geophys. Res. Space Physics, 121, 11,333-11,345. doi:10.1002/2016JA023178.

Bust, G. S., Crowley, G., Garner, T. W., Gaussiran, T. L., Meggs, R. W., Mitchell, C. N., Spencer, P. S. J., Yin, P., \& Zapfe, B. (2007), Four- dimensional GPS imaging of space weather storms. Space Weather, 5, S02003. doi:10.1029/2006SW000237.

Bust, G. S., \& Mitchell, C. N. (2008), History, current state, and future directions of ionospheric imaging, Rev. Geophys., 46, RG1003. doi:10.1029/2006RG000212

Chen, C. H., Saito, A., Lin, C. H., Yamamoto, M., Suzuki, S. \& G. K. Seemala (2016), Mediumscale traveling ionospheric disturbances by three-dimensional ionospheric GPS tomography.

Earth, Planets and Space, 68, 32. doi:10.1186/s40623-016-0412-6

Cheng, N., Song, S., Jiao, G., Jin, X., \& Li, W. (2021). Global monitoring of geomagnetic storminduced ionosphere anomalies using 3-D ionospheric modeling with multi-GNSS and COSMIC measurements. Radio Science, 56, e2020RS007074. doi:10.1029/2020RS007074

Comberiate, J. M., Kamalabadi, F., \& Paxton, L. (2006), Tomographic imaging of equatorial plasma bubbles. Geophys. Res. Lett., 33, L15805. doi:10.1029/2006GL025820

D'Angelo, G., Piersanti, M., Alfonsi, L., Spogli, L., Clausen, L. B. N., Coco, I., Li, G., \& Baiqi, N. (2018), The response of high latitude ionosphere to the 2015 St. Patrick's day storm from in situ and ground based observations. Advances in Space Research, 62, 638-650.

doi:10.1016/j.asr.2018.05.005.

Debao, W., Xiao, Z., Yangjin, T., Guangsheng, Z., Min, Z., \& Rusong, L. (2015), GPS-based ionospheric tomography with a constrained adaptive simultaneous algebraic reconstruction technique. J. Earth. Syst. Sci., 124, 283-289.doi:10.1007/s12040-015-0542-4

Fagundes, P. R., Cardoso, F. A., Fejer, B. G., Venkatesh, K., Ribeiro, B. A. G., \& Pillat V. G. (2016), Positive and negative GPS-TEC ionospheric storm effects during the extreme space weather event of March 2015 over the Brazilian sector. J. Geophys. Res. Space Physics, 121, 5613-5625. doi:10.1002/2015JA022214

Hagan, M. E., Roble, R. G., \& Hackney, J. (2001), Migrating thermospheric tides. J. Geophys. Res., 106, 12739- 12752. doi:10.1029/2000JA000344

Hairston, M. (2018) Madrigal SSIES-2 manual. Center for Space Sciences, University of Texas at Dallas.

Hairston, M., Coley, W. R., \& Stoneback R. (2016), Responses in the polar and equatorial ionosphere to the March 2015 St. Patrick Day storm. J. Geophys. Res. Space Physics, 121, 11,213-11,234. doi:10.1002/2016JA023165

This article is protected by copyright. All rights reserved. 
He, L., \& Heki, K. (2018), Three- dimensional tomography of ionospheric anomalies immediately before the 2015 Illapel earthquake, Central Chile. J. Geophys. Res. Space Physics, 123, 4015-4025. doi:10.1029/2017JA024871

Heise, S., Jakowski, N., Wehrenpfennig, A., Reigber, Ch., \& Lühr, H. (2002), Sounding of the topside ionosphere/plasmasphere based on GPS measurements from CHAMP: Initial results. Geophys. Res. Lett., 29. 44-1-44-4. doi:10.1029/2002GL014738

Hernández-Pajares, M., Juan, J. M., Sanz, J., \& Solé , J. G. (1998), Global observation of the ionospheric electronic response to solar events using ground and LEO GPS data. J. Geophys. Res., 103, 20789-20796. doi:10.1029/98JA01272

Hernández-Pajares, M., Juan, J. M., \& Sanz, J. (1999), New approaches in global ionospheric determination using ground GPS data. J. Atmos. Sol. Terr. Phys., 61, 1237-1247. doi: 10.1016/S1364-6826(99)00054-1

Hernández-Pajares, M., Lyu, H., Garcia-Fernandez, M., \& Orus-Perez, R. (2020), A new way of improving global ionospheric maps by ionospheric tomography: consistent combination of multiGNSS and multi-space geodetic dual-frequency measurements gathered from vessel-, LEO- and ground-based receivers. J. Geod., 2020, 94:73. doi:10.1007/s00190-020-01397-1

Hirooka, S., Hattori, K., Nishihashi, M., \& Takeda, T. (2011), Neural network based tomographic approach to detect earthquake-related ionospheric anomalies. Nat. Hazards Earth Syst. Sci., 11, 2341-2353. doi:10.5194/nhess-11-2341-2011.

Hsu, C.-T., Matsuo, T., Maute, A., Stoneback, R., \& Lien, C.-P. (2021), Data-driven ensemble modeling of equatorial ionospheric electrodynamics: a case study during a minor storm period under solar minimum conditions. J. Geophys Res. Space Phys., 126, e2020JA028539. doi:10.1029/2020JA028539

Huba, J. D., Sazykin, S., \& Coster, A. (2017), SAMI3-RCM simulation of the 17 March 2015 geomagnetic storm. J. Geophys. Res. Space Physics, 122, 1246-1257.

doi:10.1002/2016JA023341

Jakowski, N., \& Hoque, M. M. (2019), Estimation of spatial gradients and temporal variations of the total electron content using ground-based GNSS measurements. Space Weather, 17, 339356. doi:10.1029/2018SW002119

Juan, J. M., Rius, A., Hernández-Pajares, \& M., Sanz, J. (1997), A two-layer model of the ionosphere using global positioning system data. Geophys. Res. Lett., 24, 393-396. doi: 10.1029/97GL00092

Kelley, M.C. (1989), The Earth's Ionosphere. Elsevier Press, Amsterdam, 487 p.

Kil, H., Kwak, Y-S., Oh, S-J, Talaat, E. R., Paxton, L. J., \& Zhang, Y. (2011), The source of the longitudinal asymmetry in the ionospheric tidal structure. J. Geophys. Res., 116, A09328. doi:10.1029/2011JA016781

Kil, H., Lee, W. K., Paxton, L. J., Hairston, M. R., \& Jee, G. (2016), Equatorial broad plasma depletions associated with the evening prereversal enhancement and plasma bubbles during the 17 March 2015 storm. J. Geophys. Res. Space Physics, 121, 10,209-10,219. doi:10.1002/ 2016 JA023335.

This article is protected by copyright. All rights reserved. 
Knudsen, D., Burchill, J., Buchert, S., Eriksson, A., Gill, R., Wahlund, J.-E., Åhlén, L., Smith, M., \& Moffat, B. (2017). Thermal ion imagers and langmuir probes in the swarm electric field instruments. J. Geophys. Res. Space Phys., 122, 2655-2673. doi: 10.1002/2016JA022571

Kodikara, T., Zhang, K., Pedatella, N. M., \& Borries, C. (2021), The impact of solar activity on forecasting the upper atmosphere via assimilation of electron density data. Space Weather, 19, e2020SW002660. doi:10.1029/2020SW002660

Liu, S., Wang, J., \& Gao, J. (2010), Inversion of ionospheric electron density based on a constrained simultaneous iteration reconstruction technique. IEEE Trans. Geosci. Remote. Sens., 48, 2455-2459. doi: 10.1109/TGRS.2010.2040829

Liu, J., Wang, W., Burns, A., Yue, X., Zhang, S., Zhang, Y., \& Huang, C. (2016), Profiles of ionospheric storm-enhanced density during the 17 March 2015 great storm. J. Geophys. Res. Space Physics, 121, 727-744. doi:10.1002/2015JA021832.

Lu, G., Zakharenkova, I., Cherniak, I., \& Dang, T. (2020), Large- scale ionospheric disturbances during the 17 March 2015 storm: A model- data comparative study. J. Geophys. Res. Space Physics, 125, e2019JA027726. doi:10.1029/2019JA027726

Middleton, H. R., Pryse, S. E., Wood, A. G., \& Balthazor, R. (2008), The role of the tongueof- ionization in the formation of the poleward wall of the main trough in the European postmidnight sector. J. Geophys. Res., 113, A02306. doi:10.1029/2007JA012631.

Mitchell, C. N., \& Spencer, P. S. J. (2003), A three- dimensional time- dependent algorithm for ionospheric imaging using GPS. Ann. Geophys., 46, 687-696. doi:10.4401/ag-4373

Nava, B., Rodríguez-Zuluaga, J., Alazo-Cuartas, K., Kashcheyev, A., Migoya-Orué, Y., Radicella, S. M., Amory-Mazaudier, C., \& Fleury, R. (2016), Middle- and low-latitude ionosphere response to 2015 St. Patrick's Day geomagnetic storm. J. Geophys. Res. Space Physics, 121, 3421-3438. doi:10.1002/2015JA022299

Nayak, C., Tsai, L.-C., Su, S.-Y., Galkin, I. A., Tan, A. T. K., Nofri, E., \& Jamjareegulgarn, P. (2016), Peculiar features of the low-latitude and midlatitude ionospheric response to the St. Patrick's Day geomagnetic storm of 17 March 2015, J. Geophys. Res. Space Physics, 121, 79417960, doi:10.1002/2016JA022489

Norberg, J., Vierinen, J., Roininen, L., Orispää, M., Kauristie, K., Rideout, W. C., Coster, A. J., \& Lehtinen, M. S. (2018), Gaussian Markov Random Field Priors in Ionospheric 3-D MultiInstrument Tomography. IEEE Trans. Geosci. Remote. Sens., 56, 7009-7021. doi:10.1109/TGRS.2018.2847026

Piñón, D. A., Gómez, D. D., Smalley, R., Cimbaro, S. R., Lauría, E. A., \& Bevis, M. G. (2018), The History, State, and Future of the Argentine Continuous Satellite Monitoring Network and Its Contributions to Geodesy in Latin America. Seismological Research Letters, 89, 475-482. doi:10.1785/0220170162

Pokhotelov, D., Jayachandran, P. T., Mitchell, C. N., MacDougall, J. W. \& Denton M. H. (2011) GPS tomography in the polar cap: comparison with ionosondes and in situ spacecraft data. GPS Solut., 15, 79-87. doi:10.1007/s10291-010-0170-z

This article is protected by copyright. All rights reserved. 
Polekh, N., Zolotukhina, N., Kurkin, V., Zherebtsov, G., Shi, J., Wang, G., \& Wang, Z. (2017), Dynamics of ionospheric disturbances during the 17-19 March 2015 geomagnetic storm over East Asia. Advances in Space Research, 60, 2464-2476. doi:10.1016/j.asr.2017.09.030.

Prol, F. S., Hernández-Pajares, M. T. A. H. Muella, \& Camargo, P. O. (2018a) Tomographic Imaging of Ionospheric Plasma Bubbles Based on GNSS and Radio Occultation Measurements. Remote Sens., 10, 1529. doi:10.3390/rs10101529

Prol, F. S., Camargo, P. O., Monico, J. F. G., \& Muella, M. T. A. H. (2018b), Assessment of a TEC calibration procedure by single-frequency PPP. GPS Solut., 2018b, 22, 35. doi:

10.1007/s10291-018-0701-6

Prol, F. S., Hernández-Pajares, M., Camargo, P. O., \& Muella, M. T. A. H. (2018c), Spatial and temporal features of the topside ionospheric electron density by a new model based on GPS radio occultation data. J. Geophys. Res. Space Phys., 123, 2104-2115. doi:10.1002/2017JA024936

Prol, F. S., Camargo, P. O., Hernández-Pajares, M., \& Muella, M. T. A. H. (2019), A New Method for Ionospheric Tomography and its Assessment by Ionosonde Electron Density, GPS TEC, and Single-Frequency PPP. IEEE Trans. Geosci. Remote Sens., 2019, 57, 2571-2582. doi: 10.1109/TGRS.2018.2874974

Prol, F.S., Hoque, M. M., \& Ferreira, A. A. (2021), Plasmasphere and topside ionosphere reconstruction using METOP satellite data during geomagnetic storms. J. Space Weather Space Clim., 11, 5. doi:10.1051/swsc/2020076

Pryse, S. E., Kersley, S., Mitchell, C. N., Spencer, P. S. J., \& Willams, M. J. (1998), A comparison of reconstruction techniques used in ionospheric tomography. Radio Sci., 33, 17671779. doi:10.1029/98RS01613

Qian, L., Solomon, S. C., \& Kane, T. J. (2009), Seasonal variation of thermospheric density and composition. J. Geophys. Res., 114, A01312. doi:10.1029/2008JA013643.

Qian, L., Burns, A. G., Emery, B. A., Foster, B., Lu, G., Maute, A., Richmond, A. D., Roble, R. G., Solomon, S. C. \& Wang, W. (2014), The NCAR TIE-GCM. In Modeling the IonosphereThermosphere System (eds J. Huba, R. Schunk and G. Khazanov).

doi:10.1002/9781118704417.ch7

Ratovsky, K., Klimenko, M., Vasilyev, R., Klimenko, V., \& Podlesnyi, A. (2021), Vertical plasma transport in the ionosphere over Irkutsk during St. Patrick's Day geomagnetic storm: Observations and modeling. Advances in Space Research, 67, 122-132. doi:10.1016/j.asr.2020.10.021.

Raymund, T. D., Austen, J. R., Franke, S. J., Liu, C. H., Klobuchar, J. A. \& Stalker J. (1990), Application of computerized tomography to the investigation of ionospheric structures, Radio Sci., 25, 771-789. doi:10.3724/SP.J.1246.2011.00066

Reinisch, B. R., \& Galkin, I. A. (2011), Global ionospheric radio observatory (GIRO). Earth Planets Space, 63, 377-381. doi:10.5047/eps.2011.03.001

Richmond, A. D., Ridley, E. C., Roble, R. G. (1992), A thermosphere/ionosphere general circulation model with coupled electrodynamics, Geophys. Res. Lett., 19, 601-604. doi:10.1029/92GL00401

This article is protected by copyright. All rights reserved. 
Roma-Dollase D., Hernández-Pajares, M., Krankowski, A., Kotulak, K., Ghoddousi-Fard, R., Yuan, Y., Li, Z., Zhang, H., Shi, C., Wang, C., Feltens, J., Vergados, P., Komjathy, A., Schaer, S., García-Rigo, A., \& Gómez-Cama, J. M. (2018), Consistency of seven different GNSS global ionospheric mapping techniques during one solar cycle. J. Geod., 92, 691-706.

doi:10.1007/s00190-017-1088-9

Saito, S., Suzuki, S., Yamamoto, M., Saito, A., \& Chen, C.-H. (2017), Real-Time Ionosphere Monitoring by Three-Dimensional Tomography over Japan. Journal of The Institute of Navigation, 64, 495-504. doi:10.1002/navi.213.

Seemala, G. K., Yamamoto, M., Saito, A., \& Chen, C. H. (2014), Three-dimensional GPS ionospheric tomography over Japan using constrained least squares, J. Geophys. Res. Space Phys., 119, 3044-3052. doi:10.1002/2013JA019582

She, C., Wan, W., Yue, X., Xiong, B., Yu, Y., Ding, F., \& Zhao, B. (2017), Global ionospheric electron density estimation based on multisource TEC data assimilation. GPS Solut., 21, 11251137. doi:10.1007/s10291-016-0580-7

Ssessanga, N., Yamamoto, M., Saito, S., Saito, A., \& Nishioka, M. (2021), Complementing regional ground GNSS-STEC computerized ionospheric tomography (CIT) with ionosonde data assimilation. GPS Solut., 25, 93. doi:10.1007/s10291-021-01133-y

Tang, J., Yao, Y., Zhang, L., \& Kong, J. (2015), Tomographic reconstruction of ionospheric electron density during the storm of 5-6 August 2011 using multi-source data. Scientific Reports, 5, 13042. doi:10.1038/srep13042

Weimer, D. R. (2005), Predicting surface geomagnetic variations using ionospheric electrodynamic models. J. Geophys. Res., 110, A12307. doi:10.1029/2005JA011270.

Wen, D., Yuan, Y., Ou, J., Zhang, K., \& Liu, K. (2008), A hybrid reconstruction algorithm for 3D ionospheric tomography. IEEE Trans. Geosci. Remote Sens., 46, 1733-1739. doi:10.1109/ TGRS.2008.916466

Wen, D., Liu, S., \& Tang, P. (2010), Tomographic reconstruction of ionospheric electron density based on constrained algebraic reconstruction technique. GPS Solut., 14, 375-380.

doi:10.1007/s10291-010-0161-0

Xiong, C., Lühr, H., Ma, S., \& Schlegel, K. (2015), Validation of grace electron densities by incoherent scatter radar data and estimation of plasma scale height in the topside ionosphere. Advances in Space Research, 55, 2048-2057. doi:10.1016/j.asr.2014.07.022

Xiong, C., Lühr, H., \& Stolle, C. (2021), GRACE Electron Density derived from the K-Band Ranging System (KBR). V. 0101. GFZ Data Services. doi:10.5880/GFZ.2.3.2021.003

Yadav, S., Sunda, S., \& Sridharan, R. (2016), The impact of the 17 March 2015 St. Patrick's Day storm on the evolutionary pattern of equatorial ionization anomaly over the Indian longitudes using high- resolution spatiotemporal TEC maps: New insights. Space Weather, 14, 786-801. doi:10.1002/2016SW001408.

Yao, Y., Chen, P., Zhang, S., \& Chen, J. (2013) A new ionospheric tomography model combining pixel-based and function-based models. Advances in Space Research, 52, 614-621. doi:10.1016/j.asr.2013.05.003.

This article is protected by copyright. All rights reserved. 
Yao, Y., Tang, J., Chen, P., Zhang, S., \& Chen, J. (2014), An improved iterative algorithm for 3D ionospheric tomography reconstruction. IEEE Trans. Geosci. Remote Sens., 52, 4696-4706. doi:10.1109/TGRS.2013.2283736

Yao, Y., Zhai, C., Kong, J., Zhao, C., Luo, Y., \& Liu L. (2020), An improved constrained simultaneous iterative reconstruction technique for ionospheric tomography. GPS Solut., 24, 68. doi:10.1007/s10291-020-00981-4

Yue, X., Wang, W., Lei, J., Burns, A., Zhang, Y., Wan, W., Liu, L., Hu, L., Zhao, B., \& Schreiner, W. S. (2016), Long-lasting negative ionospheric storm effects in low and middle latitudes during the recovery phase of the 17 March 2013 geomagnetic storm. J. Geophys Res. Space Phys., 121, 9234-9249. doi:10.1002/2016JA022984

Yin, P., \& Mitchell, C. N. (2005), Use of radio-occultation data for ionospheric imaging during the April 2002 disturbances. GPS Solut., 9, 156-163. doi:10.1007/s10291-005-0143-9

Zakharenkova, I., Astafyeva, E., \& Cherniak, I. (2016), GPS and GLONASS observations of large-scale travelling ionospheric disturbances during the 2015 St. Patrick's Day storm. $J$.

Geophys. Res.: Space Phys., 121, 12138-12156. doi:10.1002/2016JA023332

Zhang, S.-R., Zhang, Y., Wang, W., \& Verkhoglyadova, O. (2017a), Geospace system responses to the St. Patrick's Day storms in 2013 and 2015. J. Geophys. Res., 122, 6901-6906.

doi:10.1002/2017JA024232

Zhang, S.-R., Erickson, P. J., Zhang, Y., Wang, W., Huang, C., Coster, A. J., Holt, J. M., Foster, J. F., Sulzer, M., \& Kerr, R. (2017b), Observations of ion-neutral coupling associated with strong electrodynamic disturbances during the 2015 St. Patrick's Day storm. J. Geophys. Res. Space Physics, 122, 1314- 1337. doi:10.1002/2016JA023307.

Zheng, D., Yao, Y., Nie, W., Yang, W., Hu, W., Ao, M., \& Zheng, H. (2018) An improved iterative algorithm for ionospheric tomography reconstruction by using the automatic search technology of relaxation factor. Radio Science, 53, 1051-1066. doi:10.1029/2018RS006588

Zheng, D., Yao, Y., Nie, W., Liao, M., Liang J., \& Ao, M. (2020), Ordered Subsets-Constrained ART Algorithm for Ionospheric Tomography by Combining VTEC Data. IEEE Trans. Geosci. Remote Sens., 59, 7051-7061. doi:10.1109/TGRS.2020.3029819.

This article is protected by copyright. All rights reserved. 